University of Wollongong

Research Online

Faculty of Engineering and Information

Faculty of Engineering and Information

Sciences - Papers: Part B

Sciences

2020

\title{
Re-examining log law velocity profile in smooth open channel flows
}

Nadeeka Miguntanna

University of Wollongong, nsm587@uowmail.edu.au

Hamish Moses

University of Wollongong

Muttucumaru Sivakumar

University of Wollongong, siva@uow.edu.au

Shu-qing Yang

University of Wollongong, shuqing@uow.edu.au

Keith Enever

University of Wollongong, kenever@uow.edu.au

See next page for additional authors

Follow this and additional works at: https://ro.uow.edu.au/eispapers1

Part of the Engineering Commons, and the Science and Technology Studies Commons

Research Online is the open access institutional repository for the University of Wollongong. For further information contact the UOW Library: research-pubs@uow.edu.au 


\title{
Re-examining log law velocity profile in smooth open channel flows
}

\begin{abstract}
2020, Springer Nature B.V. A comprehensive investigation of velocity distribution is presented, and the log law is re-examined using experimental data from a smooth uniform open channel flow. It is widely reported that the coefficients of the log law in channel flows deviate from those obtained from circular pipe flows by Nikuradse (Laws of flow in rough pipes, 1933), but the mechanism is not clear and no theoretical formulae are available to express these deviations. A Laser Doppler Velocimetry system was used to measure velocity profiles at the centre of the channel. The data obtained support previous conclusions that the additive constant B of the log law in channel flows can no longer be considered to be 5.5. Interestingly, the experimental data also support Tracy and Lester's discovery that the shear velocities on both sides of the log law are different. Better agreement can be achieved if the global shear velocity $(U * 1)$ is used to normalize the measured velocity, and the local shear velocity $(U * 2)$ is used to normalize the distance from the wall. Other researchers' data in the literature also validates this new relationship. Based on this new relationship, a theoretical value of $B$ is obtained, which agrees well with the observed $B$, thus a new form of log law for channel flow is suggested. The new relationship developed was verified with present experimental and past literature data suggesting its universality irrespective of wide or narrow open channels, or subcritical or super critical flow conditions. By using the developed relationship the large scatter associated with the additive constant B associated with the log law has been explained. It is found that the additive constant $B$ in the log law is a function of channel aspect ratio. The developed relationship for $B$ is validated from a wide range of data from the literature to confirm its universality.
\end{abstract}

\section{Disciplines}

Engineering | Science and Technology Studies

\section{Publication Details}

Miguntanna, N., Moses, H., Sivakumar, M., Yang, S., Enever, K. \& Riaz, M. (2020). Re-examining log law velocity profile in smooth open channel flows. Environmental Fluid Mechanics,

\section{Authors}

Nadeeka Miguntanna, Hamish Moses, Muttucumaru Sivakumar, Shu-qing Yang, Keith Enever, and Muhammad Zain Bin Riaz 


\title{
2 Re-examining log law velocity profile in smooth open 3 channel flows
}

\author{
4 Nadeeka S. Miguntanna ${ }^{1}$ (D) - Hamish Moses ${ }^{1} \cdot$ Muttucumaru Sivakumar $^{1}$. \\ 5 Shuqing Yang ${ }^{1} \cdot$ Keith Enever $^{2} \cdot$ Muhammad Zain Bin Riaz $^{1}$
}

6 Received: 14 January 2019 / Accepted: 23 December 2019

7 C Springer Nature B.V. 2020

\section{Abstract}

9 A comprehensive investigation of velocity distribution is presented, and the log law is reexamined using experimental data from a smooth uniform open channel flow. It is widelyAQ1 reported that the coefficients of the log law in channel flows deviate from those obtained from circular pipe flows by Nikuradse (Laws of flow in rough pipes, 1933), but the mechanism is not clear and no theoretical formulae are available to express these deviations. A Laser Doppler Velocimetry system was used to measure velocity profiles at the centre of the channel. The data obtained support previous conclusions that the additive constant B of the log law in channel flows can no longer be considered to be 5.5. Interestingly, the experimental data also support Tracy and Lester's discovery that the shear velocities on both sides of the log law are different. Better agreement can be achieved if the global shear velocity $\left(\mathrm{U}_{*_{1}}\right)$ is used to normalize the measured velocity, and the local shear velocity $\left(\mathrm{U}_{*_{2}}\right)$ is used to normalize the distance from the wall. Other researchers' data in the literature also validates this new relationship. Based on this new relationship, a theoretical value of $B$ is obtained, which agrees well with the observed B, thus a new form of log law for channel flow is suggested. The new relationship developed was verified with present experimental and past literature data suggesting its universality irrespective of wide or narrow open channels, or subcritical or super critical flow conditions. By using the developed relationship the large scatter associated with the additive constant B associated with the log law has been explained. It is found that the additive constant B in the log law is a function of channel aspect ratio. The developed relationship for B is validated from a wide range of data from the literature to confirm its universality.

Keywords Open channel flow · Laser Doppler Velocimetry (LDV) · Log law · Shear velocity · Turbulence - Uniform flow

\section{List of symbols}

A Empirical constant (-)

$B \quad$ Additive constant

$B^{\prime} \quad$ Is a function of B

\section{Nadeeka S. Miguntanna} nsm587@uowmail.edu.au

Extended author information available on the last page of the article 
$36 \mathrm{Fr}$

$\mathrm{g}$

$\mathrm{H}$

Q

$\mathrm{R}$

$1 \mathrm{Re}$

$\mathrm{S}_{\mathrm{e}}$

$43 \mathrm{~S}_{\mathrm{b}}$

$4 \mathrm{~T}$

$5 \mathrm{U}$

$6 \mathrm{U}_{*}$

$47 \mathrm{U}_{\mathrm{m}}$

$48 \mathrm{U}_{* 1}$

$49 \mathrm{U}_{* 2}$

$50 \mathrm{U}_{* \mathrm{~b}}$

$51 \mathrm{U}_{* l}$

$52 \mathrm{U}_{* \mathrm{~m}}$

$53 \mathrm{U}_{* \mathrm{r}}$

$54 \mathrm{U}_{* \mathrm{v}}$

55

56

Froude number

Gravitational acceleration $\left(\mathrm{m} \mathrm{s}^{-2}\right)$

Flow depth (m)

Flow discharge $\left(\mathrm{L} \mathrm{s}^{-1}\right)$

Hydraulic radius (m)

Reynolds number based on hydraulic radius

Energy slope (-)

Bed slope (-)

Water temperature $\left({ }^{\circ} \mathrm{C}\right)$

Streamwise time averaged velocity $\left(\mathrm{m} \mathrm{s}^{-1}\right)$

Shear velocity $\left(\mathrm{m} \mathrm{s}^{-1}\right)$

Depth averaged mean velocity at the centre $\left(\mathrm{m} \mathrm{s}^{-1}\right)$

Global shear velocity $\left(\mathrm{m} \mathrm{s}^{-1}\right)$

Local shear velocity $\left(\mathrm{m} \mathrm{s}^{-1}\right)$

$\mathrm{U}_{*}$ based on bed slope $\left(\mathrm{m} \mathrm{s}^{-1}\right)$

$\mathrm{U}^{*}$ evaluated from clusters method $\left(\mathrm{m} \mathrm{s}^{-1}\right)$

Measured shear velocity $\left(\mathrm{m} \mathrm{s}^{-1}\right)$

Shear velocity evaluated from Reynolds stress distribution $\left(\mathrm{m} \mathrm{s}^{-1}\right)$

$\mathrm{u}, \mathrm{v}, \mathrm{w}$ Instantaneous velocities in $\mathrm{x}, \mathrm{y}$ and $\mathrm{z}$ direction $\left(\mathrm{m} \mathrm{s}^{-1}\right)$

W Width of the channel (m)

$\mathrm{X}, \mathrm{Y}, \mathrm{Z}$ Streamwise, vertical and transverse coordinates respectively $(\mathrm{m})$

y Vertical distance from the solid boundary (channel bottom)

Density of water $\left(\mathrm{kg} \mathrm{m}^{-3}\right)$

von Karman constant

Kinematic viscosity of the fluid $\left(\mathrm{m}^{2} \mathrm{~s}^{-1}\right)$

Distance from the bottom where $\mathrm{U}=\mathrm{U}_{\mathrm{e}}(\mathrm{m})$

\section{Introduction}

Turbulence characteristics or most particularly velocity distributions of open channel flows are of great importance in many fields such as hydraulic engineering, environmental engineering, fluid mechanics and physics $[3,5,6,28,33,36,58,59]$. Phenomena such as diffusion of matter as well as erosion, transport and abrasion and deposition of sediments or flow resistance are directly governed by the flow characteristics. Such flow characteristics include: the distribution of time averaged velocities, turbulence intensity distributions, and Reynold shear stress distributions [1-3, 5-8, 11, 21, 28, 46, 62, 64]. An extensive review and analysis by George et al. [20] reported that turbulent flow is the most investigated aspect of channel flows. This is not surprising from a practical viewpoint as turbulent flows are encountered in many industrial and environmental applications. For example, the estimation of mixing of pollutants in water bodies and sediment transport rates in open channels are directly influenced by the nature of the flow. Further, accurate estimation of turbulent characteristics or more particularly velocity distribution is crucial in river development and management, reservoir operation, and flood protection. Consequently, in the two-dimensional analysis of fluid flow, the mean velocity distributions in open channels are of great interest to engineers. 
In an early study, Tracy and Lester [59] studied the velocity distribution in a wide rectangular open channel and they concluded that the open channel flow could be divided into two portions; one in the central portion and the other in the vicinity of the wall termed the corner portion. Due to the practical and theoretical importance of the problem, extensive experimental and analytical investigations have been carried out since 1930 to determine the vertical distributions of velocities for turbulent flows over smooth and rough surfaces [6, 20, 26, 33, 36-39, 52, 54, 60]. As discussed in Sarma et al. [49], the theoretical investigations of Prandtl [44], von Karman [61] and the experimental studies of Nikuradse [41] on flow through pipes have led to conclusive knowledge of velocity distribution and hydraulic resistance of turbulent flows in circular pipes. This knowledge has later been extended to open channel flows with modifications [6, 36, 39, 54]. Although some general similarities exist between the flow through pipes and the flow through open channels, certain factors such as the presence of a free surface, the three-dimensional nature of the flow due to noncircular cross section of the channel, and non-uniform distribution of shear along the wetted perimeter, distinguish open channel flow from pipe flow.

Though much work has been conducted with regard to turbulence of open channel flows, velocity distribution in open channels is still not fully understood. According to Balachandar et al. [7], lack of understanding of structural characteristics of turbulence in open channel flows inhibits practical applications. Hence, more research on this area is of crucial importance. Such knowledge is indispensable in understanding the hydraulics which govern uniform open channel flows. Consequently, accurate estimation and proper understanding of velocity profiles of uniform open channel flows is paramount as this is the key aspect of turbulent structure. According to the review conducted, it is interesting to note that log law velocity profiles are differently presented in literature with a universal von Karman constant $(\kappa)$ and an additive or integration constant (B) which show a large scatter. Although Tracy and Lester [59] found that the shear velocities are different on both sides of the log-law, only a handful researchers (As an example; Yang et al. [63] paid attention to it, and no connection has been established between the variations of B with other readily measurable parameters. This aspect is extensively discussed in this paper. Consequently, the formulated objectives of the present study are to: (1) examine experimentally the proper definition of shear velocities in the log law using experimental data; (2) to investigate the mechanism that causes the observed $\kappa$ and $B$ in channel flows to deviate from Nikuradse values; (3) to justify the large scatter of the additive constant (B) in the log law; and to test the applicability of the proposed equation with experimental and literature data.

In the present study, velocity measurements were taken using a 2D Laser Doppler Velocimetry (LDV) system. This is a well-established, non-intrusive and powerful measurement technique that gives information about instantaneous flow velocities in 2 directions $[6,18,38]$. All the velocity measurements were taken in the fully developed turbulent region of sub-critical flows on smooth rectangular open channels of finite aspect ratios. An extensive experimental program was conducted to obtain accurate data sets and hence provide more conclusive outcomes. Special attention was given to the determination of the shear velocities that are obtained using measured velocity distributions. With the results obtained from the present experiments, the law of the wall of the mean velocities or the log law on smooth beds are re-examined. In the following section, some of the theoretical information related to the present study is reviewed. 


\section{Theoretical considerations}

\subsection{The law of the wall}

As discussed above, over past decades, various comprehensive research studies have been conducted on the mean flow characteristics of fully developed, two dimensional (2D) open channel flows over smooth and rough beds. The key objective of these studies was to advance the understanding of turbulent flows and to quantify important flow parameters. These studies indicate that the boundary layer of open channel flow consists of two selfsimilar regions namely the inner region and the outer region described by different scaling laws $[6,12,26]$ (see Fig. 1). The inner region of a turbulent layer is much narrower than the outer region. Its thickness represents $10-20 \%$ of the entire boundary layer thickness [15]. In the inner region the mean velocities are generally controlled by the wall shear stress, wall roughness, distance from the wall, density, and viscosity of the fluid [26]. The inner region consists of two distinct parts, namely: the viscous sublayer and the fully turbulent part. Experiments by several researchers $[15,26]$ showed that the total shear stress at some small distance from the wall is constant and equals the wall shear $\tau_{0}$. Therefore, the integration of Newton's law of viscosity $\left(\tau=\mu \mathrm{du} / \mathrm{dy}\right.$ with $\left.\tau=\tau_{0}\right)$, gives the velocity distribution in the viscous sublayer as:

$$
\frac{U}{U_{*}}=\frac{U_{*} y}{v}
$$

where $\mathrm{U}=$ streamwise time averaged velocity $\left(\mathrm{ms}^{-1}\right) ; \mathrm{U}_{*}=\left(\tau_{0} / \rho\right)^{0.5}=$ the friction velocity; $\rho=$ the density; $v=$ the kinematic viscosity of the fluid; and $y=$ the distance from the solid boundary.

In the fully turbulent part of the inner region, the logarithmic velocity distribution equation of von Karman-Prandtl is universally recognized as the logarithmic portion of the "law of the wall" [37, 50, 57, 61]. The logarithmic velocity distribution equation takes the following form:

$$
U^{+}=A \ln \left(Y^{+}\right)+B
$$

where,

Fig. 1 Sketch of a classical representative velocity profile in open-channels. (Adapted from Ben Meftah and Mossa [9])

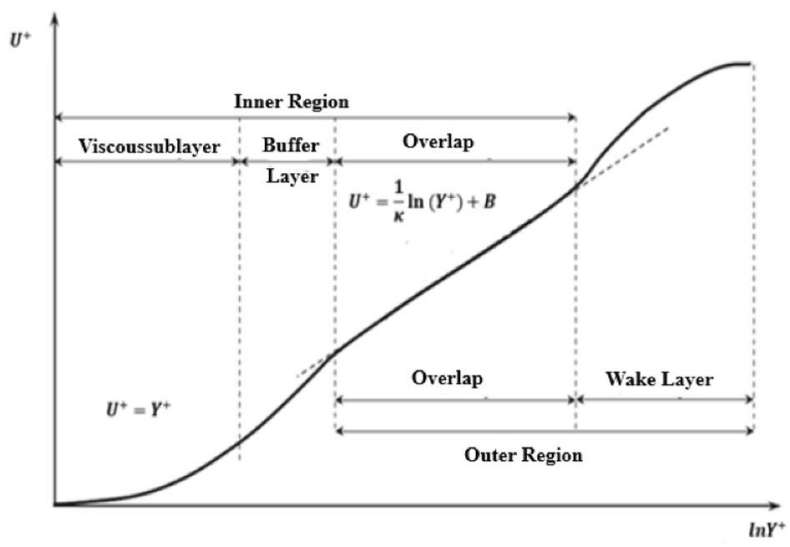




$$
U^{+}=\frac{U}{U_{*}} ; Y^{+}=\frac{y U_{*}}{v} \quad \text { and } \quad A=\frac{1}{\kappa}
$$

in which $\kappa$ is the universal von Karman constant, which is independent of the nature of the wall, whether smooth or rough, and B is a constant whose value depends on the nature of the wall surface [26, 50]. Initially, Nikuradse [41] found, after conducting the experiments for hydraulically "smooth" pipe flow, that $A=2.5$; with $\kappa$ as 0.4 and $B=5.5$. Keulegan [25] assumed that in any open channel flows, Eq. (2) could express the mean velocity distribution for fully developed turbulent flow with Nikuradse's values of constants. Nevertheless, most recently researchers have found different values for constants A and B after conducting their own experiments. As an example, Nezu and Rodi [38] conducted experiments with LDV in a uniform, subcritical turbulent open channel flow over a smooth bed and stated that Eq. (2) can be applied to the near wall region and both A and B remain constant at $A=2.44$ with $\kappa=0.41$ and $B=5.29$. These values are slightly different from those suggested by Nikuradse [41] for pipe flows with $\kappa=0.40$ and $B=5.5$. Values ranging from 5.0 to 5.5 have been commonly used by Roussinova [46] for B.

After a significant number of studies researchers recommended that the value of $\kappa=0.41$ is an acceptable value [5, 7, 13, 26, 27]. Balachandar et al. [7] confirmed that $\kappa=0.41$ for shallow, low Reynolds number, open channels with the certainty of $\kappa=0.41 \pm 5 \%$ which is widely accepted for steady, fully developed closed and open channel flows over smooth, rough and even movable beds irrespective of the Reynolds and Froude numbers [5, 13, 24, 27, 37, 45, 56] (see Fig. 2). In contrast, the constant B has been subject to large variations dependent on flow properties as shown in Fig. 3. According to Zanoun [66], this scatter could be attributed either to inconsistencies in the general trends of the available experimental data which might be related to improper measuring equipment, inaccurate measurement of the shear velocity, $U_{*}$, or due to low Reynolds numbers, i.e., $\operatorname{Re}<10^{3}$, effects.

The modern theory of turbulence indicates that (as an example [37]) the log law is valid only in the wall region for $\mathrm{y} / \mathrm{H}<0.2$ where $\mathrm{H}$ is the flow depth or the boundary layer

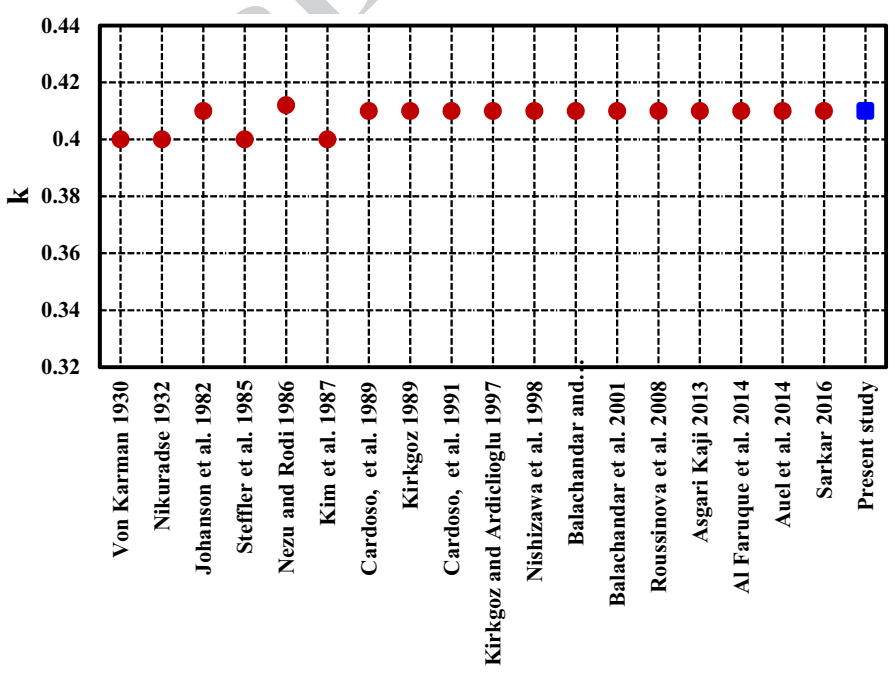

Fig. 2 Values of the von Karman constant of the logarithmic law of the wall obtained from various investigations 


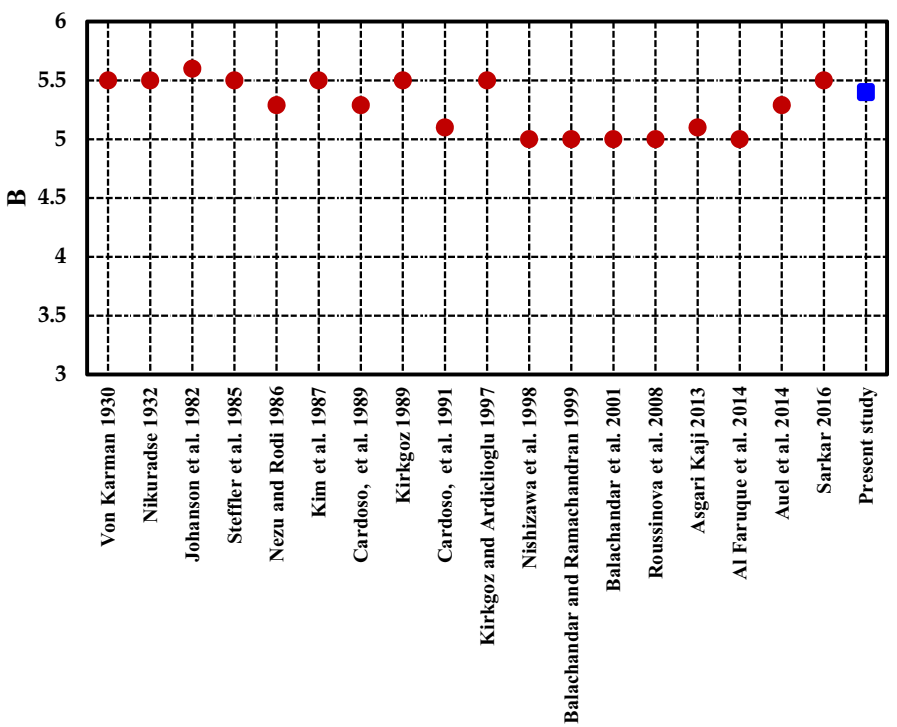

Fig. 3 Values of the integration constant (additive constant) 'B' of the logarithmic law of the wall obtained from various investigations

thickness. However, it is worth noting that there are slight discrepancies in the literature with regard to the boundaries of this region. Nezu and Rodi [38] and Steffler et al. [51] examined the log law distribution in the wall region of open channel flows using LDV and noted that experimental values of the non-dimensional mean velocity $\mathrm{U}+$ in the region of $30<\mathrm{Y}^{+}<0.2 \mathrm{Re}^{*}$ coincide well with the log law. Here $\mathrm{Re}^{*}$ refers to the Reynolds number based on shear velocity as:

$$
\operatorname{Re}^{*}=\frac{U_{*} H}{v}
$$

Later, Roussinova $[46,47]$ noted that for sufficiently high Reynolds number, an inertial sublayer or logarithmic layer exists roughly in the region $30 \leq Y+\leq 300$, and $\mathrm{y} / \mathrm{H}<0.2$. In addition, Kirkgoz [26] found that for a range of Reynolds numbers, the log law is valid in the range of $50-80 \leq \mathrm{U} * \mathrm{y} / \mathrm{v} \leq 200-600$ where $0.14-0.05 \leq \mathrm{y} / \mathrm{H} \leq 0.6-0.5$. In contrast, Cardoso et al. [13], after conducting independent experiments, suggested that the log law is applicable for the entire channel length. Additionally, most recently Zanoun et al. [66] also found an increase of the upper limit, which is $\mathrm{y} / \mathrm{H}=0.2$, by $75 \%$ after analysing the data for a wide range of Reynolds numbers.

\subsubsection{Determination of shear velocity $\left(U_{*}\right)$}

In depth understanding of velocity distribution in open channel flows requires accurate evaluation of the shear velocity $\mathrm{U}_{*}$, which is one of the most decisive parameters. This is the most fundamental velocity scale, which can be used to normalize mean velocity and turbulence. Researchers use different methods to determine the shear velocity. The most common methods, which are widely used to estimate shear velocity, are shown 


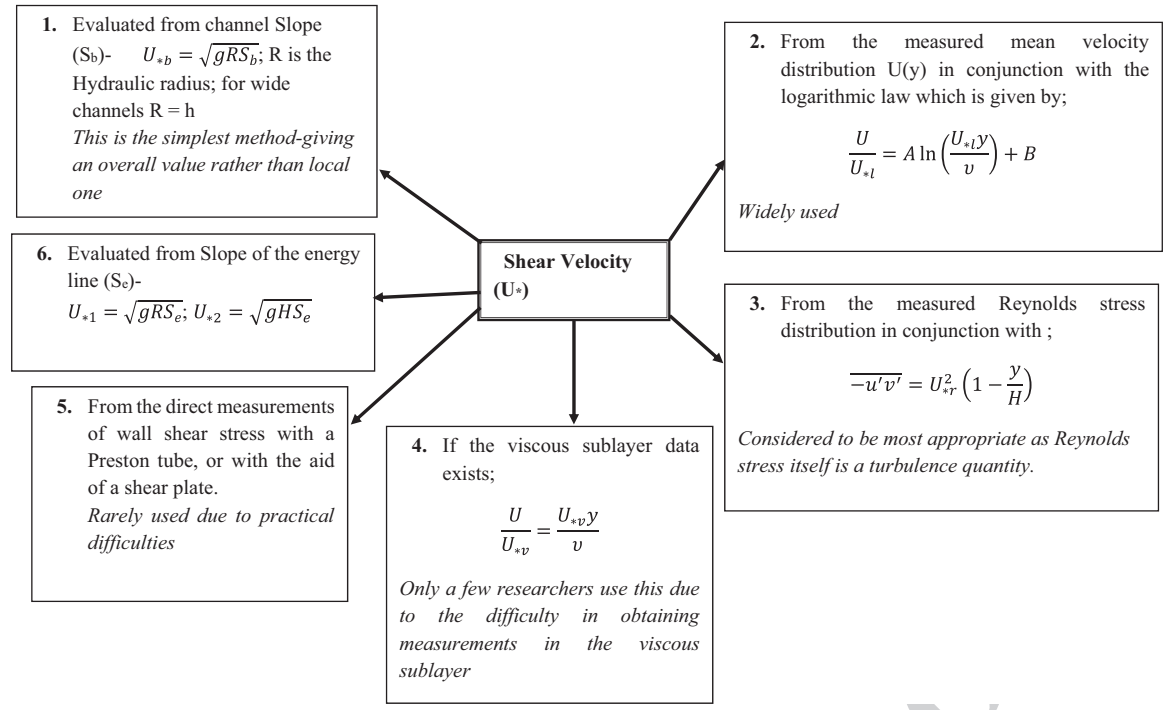

Fig. 4 Methods to determine shear velocity $\left(U_{*}\right)$

in Fig. 4. Some of the past investigations on turbulent open channel flows in relation to different techniques that have been used to estimate $U_{*}$ are summarized in Table 1 . Due to the difficulties associated with direct measurement of the wall shear stress $\tau_{0}$, $\mathrm{U}_{*}$ is usually calculated by indirect methods. As seen in Table 1 direct measurement of $U_{*}$ is rare and most widely used methods are methods 1,2 and 3. With regards to methods 1 and 6 researchers directly used bed slope instead of using energy slope $\left(\mathrm{S}_{\mathrm{e}}\right)$ under uniform flow conditions. However, when considering non-uniformity, use of $\mathrm{S}_{\mathrm{e}}$ will always give a more accurate estimation of $\mathrm{U}_{*}$.

\subsubsection{Use of shear velocity in the log law obtained from different methods}

After a critical review of the literature, it was understood that the most common applications of $\mathrm{U}_{*}$ in the log law are; use of either $\mathrm{U}_{*_{l}}$ or $\mathrm{U}_{*_{\mathrm{r}}}$ or $\mathrm{U}_{*} v$ or $\mathrm{U}_{*_{1}}$ or $\mathrm{U}_{*_{2}}$ on both sides of $\log$ law as velocity scales and length scales. Most of the researchers use identical shear velocities on both sides of log law equation evaluated from one of these methods. Most of the researchers argued that use of $U_{*_{l}}, \mathrm{U}_{*_{\mathrm{r}}}$ or $\mathrm{U}_{*_{\mathrm{v}}}$ is most accurate to use in the log law equation in comparison to the other methods $[6,26,27,46,48]$. It is interesting to note that when researchers used $U_{*_{1}}$ or/and $U_{*_{2}}$ in the log law either $\mathrm{U}_{*_{1}}$ or $\mathrm{U}_{*_{2}}$ is used on both the left and right hand sides of the log law equation (Eq. 2). It is common practice to use either $\mathrm{U}_{*_{1}}$ or $\mathrm{U}_{*_{2}}$ at the same time on both sides of the equations. For wide open channels where Hydraulic radius $(\mathrm{R})$ can be replaced with $\mathrm{H}$, $\mathrm{U}_{*_{1}}$ and $\mathrm{U}_{*_{2}}$ become similar. It is worth noting that, to the authors' knowledge, none of the authors in the literature have used both $\mathrm{U}_{*_{1}}$ and $\mathrm{U}_{*_{2}}$ simultaneously in the log law except Yang et al. [63]. This is further described in Sect. 2.2. 


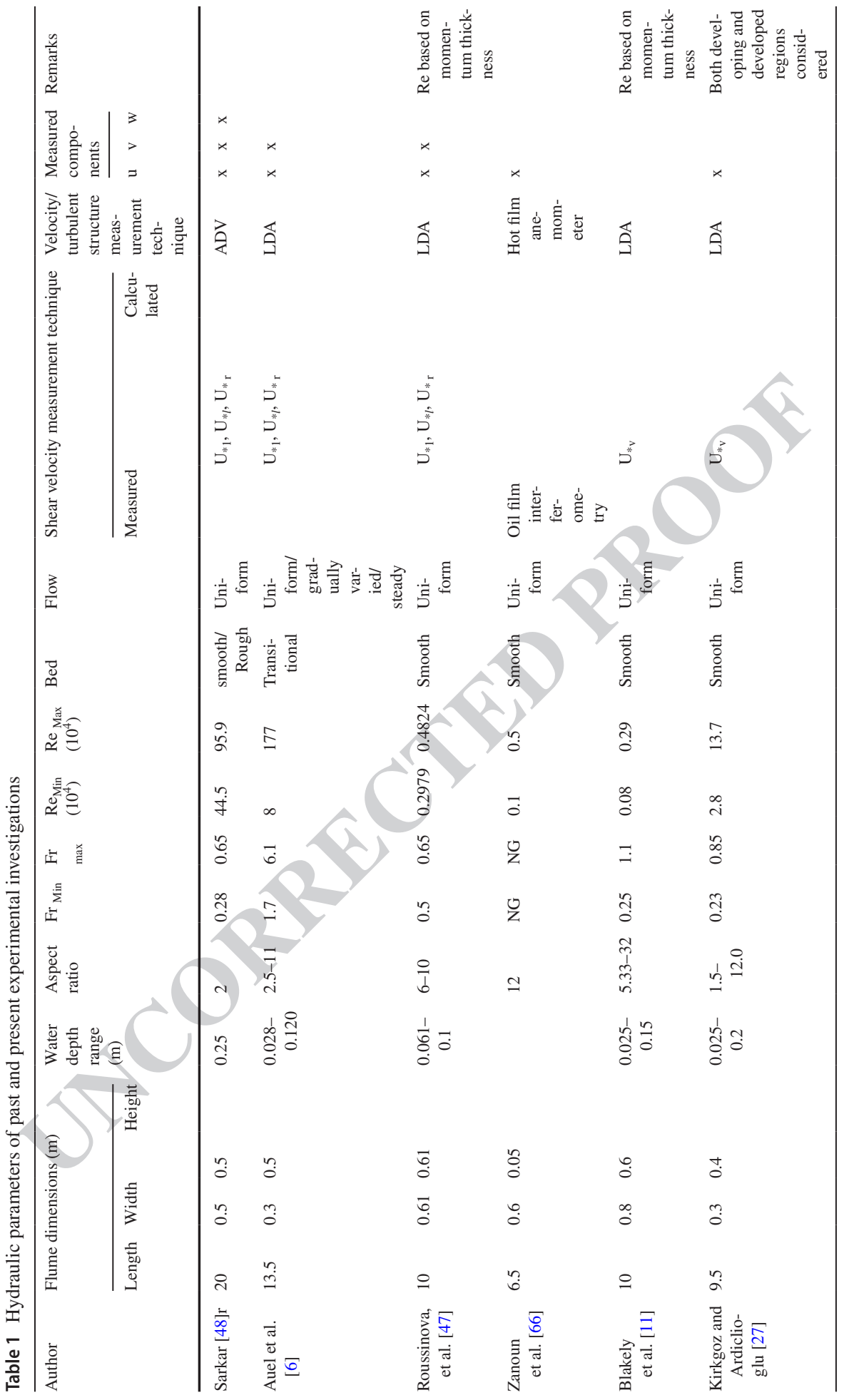




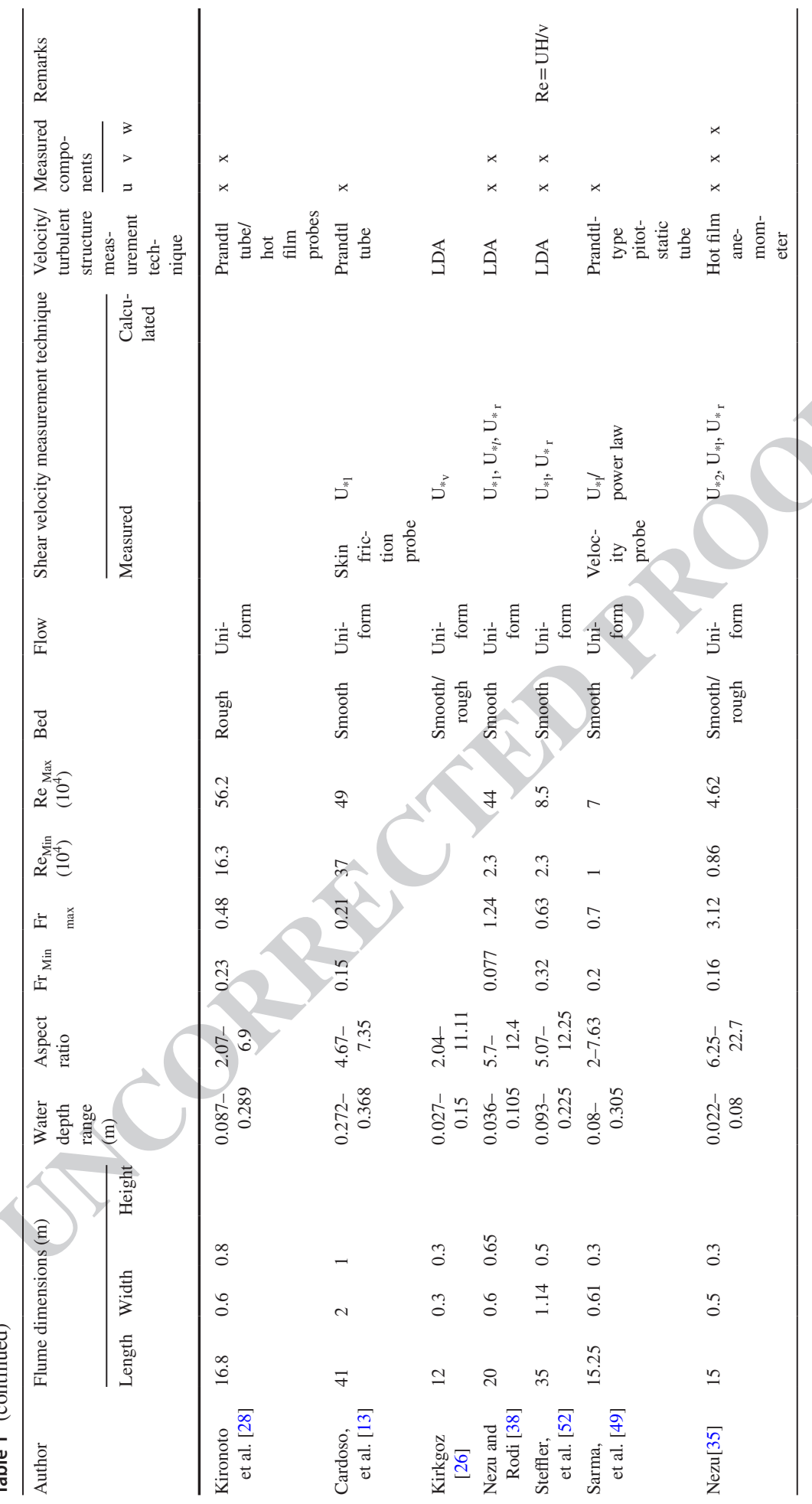




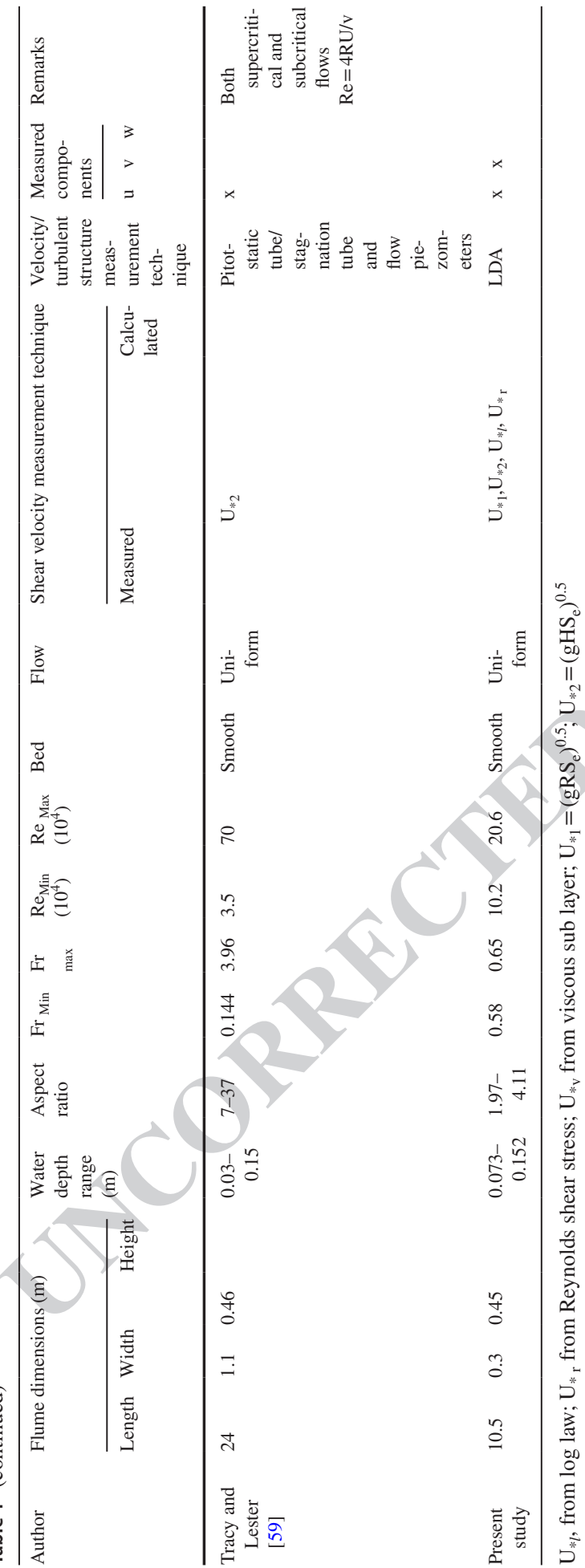




\subsection{Introducing New Scalings to the Log Law}

As discussed above the Prandtl-von Karman equation should be valid to express the central velocity profiles in smooth open channel flows. However, as investigated by Tracy and Lester [59] the shear velocities are not the same on both sides of the log law of Eq. (2) for the channel centre line. Experimental conditions of Tracy and Lester [59] are given in Table 1. Based on their measured data, they found that $U / U_{*_{2}}$ against $U_{*_{2}} y / \nu$ does not collapse to a single line after plotting it in semi-log form (see Fig. 5a). They replaced $\mathrm{U} / U_{*_{2}}$ with normalized $\mathrm{U} / U_{*_{1}}$ and replotted in the form of $U / U_{*_{1}}$ versus $U_{*_{2}} y / \nu$, and observed that the data points collapsed onto a single line (see Fig. 5b) which is given by;

$$
\frac{U}{U_{* 1}}=A \ln \left(\frac{y U_{* 2}}{v}\right)+B
$$

Tracy and Lester [59] concluded that if local shear velocity and global shear velocity are used to normalize the measured near-wall velocity and wall normal distance respectively, then the well-known wall function can be used to describe the near wall velocity. Tracy and Lester [59] did not explain why the shear velocities should be different on both sides of Eq. (4) to obtain the good agreement in Fig. 5b. As far as we are aware, there is only a single study, that of Yang et al. [63], which uses two shear velocities in a velocity plot that is different from the widely used wall function suggested by Keulegan [25]. However, they only focused on near wall velocity or the corner regions of 3D smooth channel flows.

More recently, Yang et al. [63] extended the discovery of Tracy and Lester [59] for both boundary regions (wall or bed) besides the centre line i.e., $U_{* 1}=\left(g R S_{e}\right)^{0.5}$ and $U_{* 2}=\left(g H S_{e}\right)^{0.5}$ and further confirmed that shear velocities are different from each other as in Eq. (4). As described in Tracy and Lester [59] and Yang et al. [63] global shear velocity $\left(U_{* 1}\right)$ depends on cross section of the channel whereas local shear velocity $\left(\mathrm{U}_{* 2}\right)$ depends on normal distance from the wall or bed of the channel. Irrespective of whether the channel is narrow or wide, the normal distance depends on division lines. Therefore, Tracy and Lester [59] and Yang et al. [63] postulated that $\mathrm{U}_{*_{2}}$ is the same for narrow and wide channels using the concept of division lines and the concept of boundary shear stress. Further, Yang et al. [63] highlighted the need to partition the flow region and the need to use different shear velocities on both sides of the log law in 3-D channel flows. In addition to Tracy and Lester [59], Yang et al. [63] used three other researchers' data obtained from NHRI [40], Yassin [65] and Kirkgoz and Ardichoglu [27] representing shallow wide channel with $\mathrm{W} / \mathrm{H}>5$, representing narrow deep and wide shallow channels with W/H- 1-3 and representing narrow to wide channels with W/H-1-12 respectively to confirm their relationships which are described in Yang et al. [63].

Equation (4) is critically explored with experimental data obtained in this study. The results indicate a very good agreement with the theoretical equation of the law of the wall for a wide range of experimental data obtained in this study and in the literature.

Now, let us expand Eq. (4):

$$
\frac{U}{U_{* 1}}=A \ln \left(\frac{y U_{* 1}}{v} \times \frac{U_{* 2}}{U_{* 1}}\right)+B
$$



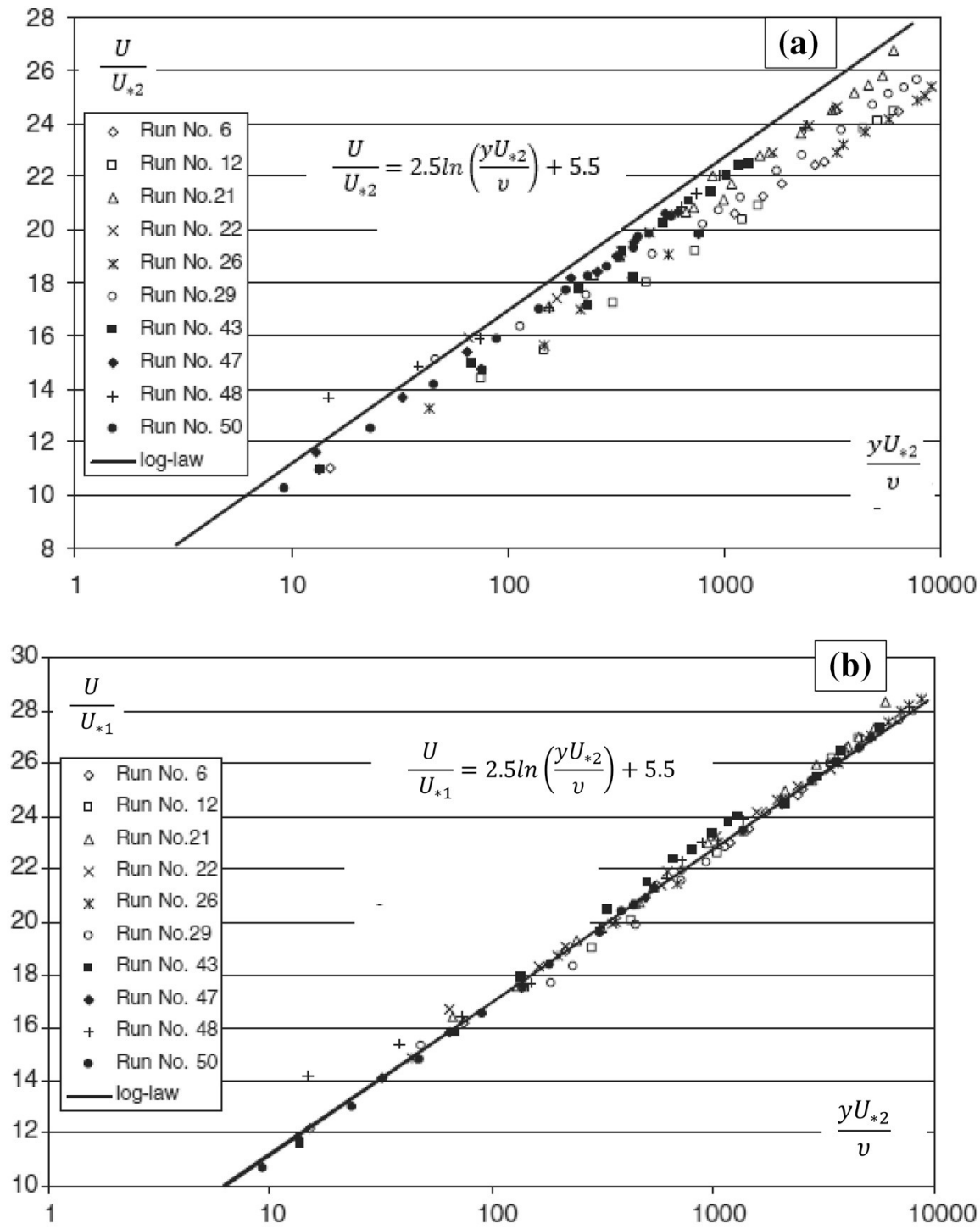

Fig. 5 a Measured centreline velocity distribution for smooth channel (after Tracy and Lester [59]). b Reproduction of point velocity shown in (a) using different shear velocities (after Tracy and Lester [59]) 


$$
\frac{U}{U_{* 1}}=A \ln \left(\frac{y U_{* 1}}{v}\right)+\underbrace{A \ln \left(\frac{U_{* 2}}{U_{* 1}}\right)+B}_{\mathbf{B}^{\prime}}
$$

$$
B^{\prime}=A \ln \left(\frac{U_{* 2}}{U_{* 1}}\right)+B
$$

$$
B^{\prime}=A \ln \left(\frac{\left(\sqrt{g H S_{e}}\right)}{\sqrt{g R S_{e}}}\right)+B
$$

$$
B^{\prime}=\frac{1}{2} A \ln \left(\frac{H}{R}\right)+B
$$

276 when $\mathrm{R}=\mathrm{H}$ for wide open channels; $\mathrm{B}^{\prime}$ tends to $\mathrm{B}$ which is the typical equation of the log 277 law as discussed so far.

\section{Experimental set-up and measurement techniques}

279 Experiments were conducted under controlled laboratory conditions utilizing the flume 280 facility that is available in the School of Civil, Mining and Environmental Engineer281 ing Hydraulics laboratory, University of Wollongong, Australia. The experiments were
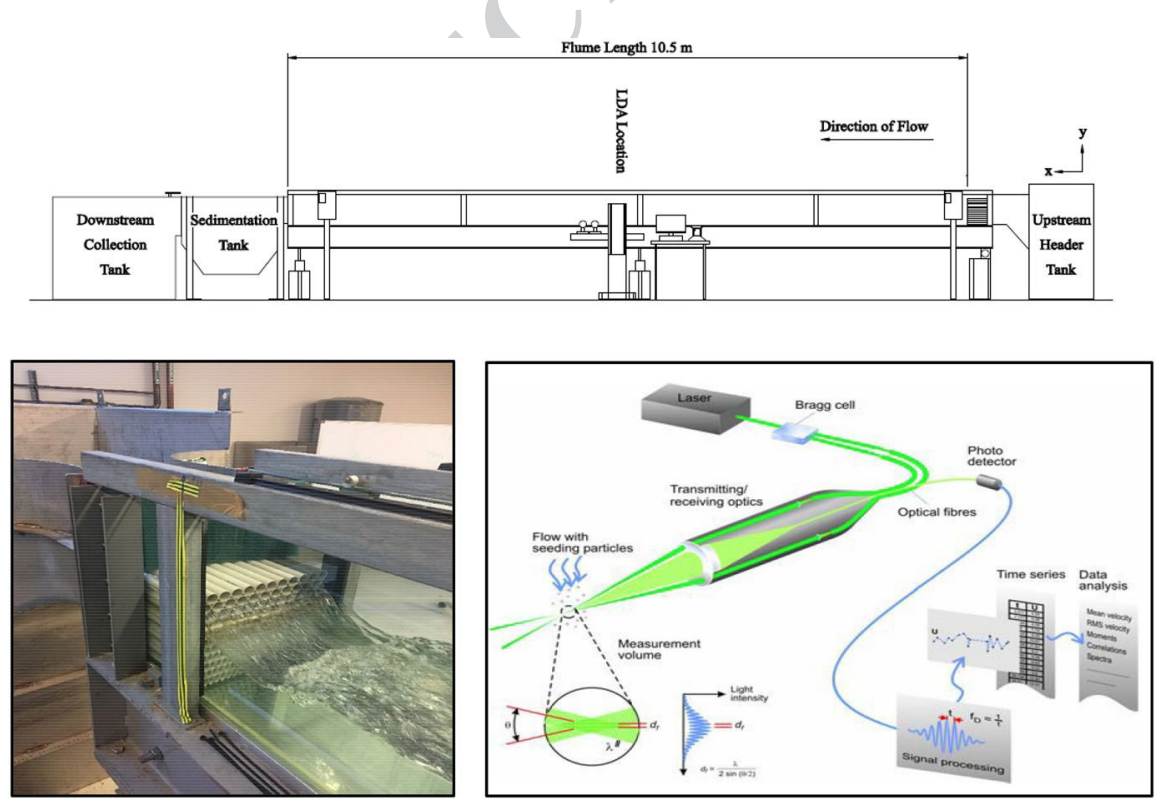

Fig. 6 Experimental set-up 
performed in a $10.5 \mathrm{~m}$ long, $0.3 \mathrm{~m}$ wide and $0.45 \mathrm{~m}$ high rectangular glass walled flume (Fig. 6). The bed slope $\left(S_{b}\right)$ was fixed to 0.001 . The coordinates in the streamwise, vertical and spanwise directions are $\mathrm{X}, \mathrm{Y}$ and $\mathrm{Z}$ respectively. The instantaneous velocities in each direction are denoted as $\mathrm{u}, \mathrm{v}$ and $\mathrm{w}$ in the $\mathrm{X}, \mathrm{Y}$ and $\mathrm{Z}$ directions respectively. A series of baffles and a honeycomb section with rods in a staggered configuration were located at the entrance to the flume to ensure uniform velocity distribution within the channel cross section (Fig. 6). Baffle walls were provided in series to decrease the effect of turbulence of the incoming water. The flow of the flume was generated using a $40 \mathrm{~L} / \mathrm{s}$ pump connected to the head tank. Bleed valves were incorporated in the plumbing system to release excess pump pressure. An electromagnetic flow meter (F-2000 from Blue White Industries Ltd) was fixed to the pumping system to monitor the flow rate. The flow rate through the flume was controlled by the pump's frequency at a control box. More details of the flume and its components are available in Gamage [19].

A 2D-laser Doppler velocimetry (LDV) system was used as the main velocity measurement technique (Fig. 6). This is a two component configuration with a $60 \mathrm{~mm}$ optical fibre probe and a front lens with a $400 \mathrm{~mm}$ focal length. The system consists of a $300 \mathrm{~mW}$ continuous wave Argon-Ion laser and transmitting optics that include a beam splitter, Brag cell and signal processors. Green $(514.5 \mathrm{~nm})$ and blue $(488 \mathrm{~nm})$ components were used to measure the horizontal and vertical components of the velocity, respectively. The optics for 2-D LDV were arranged in an off-axis back scatter mode. The back scatter mode of receiving a signal from a particle refers to the reflected light being captured by the receiving optics on the same side as the incident laser beams, with reflected light going back into the probe head through the front lens. The wave length of the measured volume was approximately $0.189 \times 0.189 \times 3.97 \mathrm{~mm}$ for both colours, when measured in air. The characteristics of the LDV system used are summarised in Table 2. A more complete description of the LDV system used is found in [22] and [23].

All the experiments needed to be conducted in the fully developed flow region. Depending upon the extent of inlet smoothing and upstream flow uniformity, the minimum length to achieve fully developed uniform conditions will obviously vary significantly $[27,38]$. By considering the recommended locations from Kirkgoz and Ardichoglu [27], Gamage [19] and Han [22] the test section was initially set up at $6.5 \mathrm{~m}$ downstream from the channel entrance. However, to further ensure that the fully developed flow was achieved at this entry length, measurements of streamwise time averaged velocity (U) along different water depths were obtained along the total width of the channel for all the tests. Transverse flow profiles were obtained using both LDV and a propeller meter in several cross sections along the channel. As can be seen in Fig. 6, the LDV was located at $X=6.5$ metres which represents the fully developed flow section for

Table 2 Characteristics of LDV system used

\begin{tabular}{ll}
\hline Wavelength, $\lambda(\mathrm{nm})$ & 500 \\
Beam separation, ED $(\mathrm{mm})$ & 38 \\
Beam diameter, Ed $(\mathrm{mm})$ & 2.2 \\
Receiver aperture, $\mathrm{Da}(\mathrm{mm})$ & 47 \\
Focal length, f $(\mathrm{mm})$ & 400 \\
Measuring volume diameter, dx $(\mu \mathrm{m})$ & 189 \\
Measuring volume length, dz $(\mathrm{mm})$ & 3.97 \\
Fringe separation, $\delta(\mu \mathrm{m})$ & 5.27 \\
Fringe number & 36 \\
\hline
\end{tabular}


all the tests and hence is taken as the measurement station. Flow depth was measured with point gauges of $\pm 0.1 \mathrm{~mm}$ accuracy. The depth of water through the flume was controlled by an adjustable tailgate in the downstream collection tank. To attain steady and uniform flow conditions, the water surface slope was kept parallel to the bed slope for each experiment.

The authors aimed at obtaining reliable information regarding the mean velocity distribution in two-dimensional fully developed turbulent open channel flow. As discussed above, transverse profiles were obtained throughout the channel cross section. Vertical profiles of streamwise velocity were obtained at the centre of the flow from bottom to top of the water surface where the flow is supposed to be the least affected by three-dimensionalities [26]. In order to minimise the experimental error from sources contributing to the uncertainty of the LDV results, setting up the experiment was done very carefully. The entire LDV system was re-calibrated and carefully set by DANTEC in order to minimize the errors as much as possible. The techniques adopted for this purpose are well described in the literature [16, 17, 22, 29]. A number of trial tests and repetitive tests were performed on different days at different times to ensure the entire system was properly configured to conduct experiments.

The signal processor which is used in the present LDV system is a Dantec Burst Spectrum Analyser (BSA) which is connected to an oscilloscope and a PC. The BSA converts the electrical signals, which are processed by the oscilloscope, into velocity data, which are monitored online by a PC. Raw data exported from the BSA can be processed into statistical values like ensemble-averaged measurements of velocity, root mean squared values of velocity fluctuations, and Reynolds stresses. In order to obtain mean velocity and other statistical data accurately it is important to choose the appropriate sample size [23, 43, 67]. Hence, throughout our current experiments the size of the sample chosen was 2000 which gives the likely relative error as only around $0.09 \%(<2 \%)$ which can be considered to be sufficient for the two component LDV in the current configuration Han et al. [23] and Peltier et al. [43]. The sampling time used was $20 \mathrm{~s}$ and the acquisition frequency was $100 \mathrm{~Hz}$. Furthermore, in order to obtain accurate measurements, it was paramount that the seeding particles within the fluid were distributed uniformly and homogenously. This was achieved by keeping the seeding between 8 and $11 \mathrm{ppm}$ as described in Han et al. [23]. Further, in order to eliminate velocity bias the system was operated at high signal rates, properly time averaging the processor output as described in DANTEC [17].

After ensuring the experimental set up was working properly with all its components, altogether six test runs for six flow rates were conducted and both transverse and vertical velocity profiles were taken for each test. Transverse profiles were taken from wall to wall of the channel for each discharge at different flow depths. Vertical velocity profiles were taken at the centre of the channel as mentioned above. Considering the limitations of the present LDV system, acquisition of data in the viscous layer, which is extremely close to the bed of the channel, was not possible. However, data was successfully obtained in the $\log$ region with an error of less than $1 \%$. The calculation of the uncertainty of $1 \%$ is based on statistical analysis of repetitive experimental runs $[4,10,32,55]$. Velocity measurements were taken in $0.1 \mathrm{~mm}$ or $0.2 \mathrm{~mm}$ intervals depending on water depth up to $50 \mathrm{~mm}-60 \mathrm{~mm}$ from the bottom of the channel by using the traverse system attached to the LDV which facilitates obtaining the velocity measurements in the given sample volume in Table 2 with a $\pm 300 \mu \mathrm{m}$ accuracy. Experimental uncertainties were found to be less than $1.5 \%$ for streamwise time averaged velocity measurements and $3 \%$ for the root mean square (RMS) velocity fluctuation measurements. The low uncertainties obtained in the measurements highlight the validity and robustness of the relationships described in this study. 


\section{Experimental results, analysis and discussion}

\subsection{Hydraulic conditions}

As discussed above, flow measurements were conducted for six different experiments, with the measured and calculated hydraulic parameters listed in Table 3 . The investigated flows are characterized by a narrow range of flow Reynolds numbers, $R e=4 \mathrm{U}_{\mathrm{m}} \mathrm{R} / v$, by moderately high Froude numbers, $\mathrm{Fr}=\mathrm{U}_{\mathrm{m}} /(\mathrm{gH}){ }^{(0.5)}$ (g is the gravitational acceleration and $\mathrm{U}_{\mathrm{m}}$ is the depth average mean velocity at the channel centre), and by aspect ratios in the range $1.97<\mathrm{W} / \mathrm{H}<4.11$. As seen in Table 3, maximum velocity $\left(\mathrm{U}_{\mathrm{e}}\right)$ varied between $0.624 \mathrm{~m} / \mathrm{s}$ to $0.802 \mathrm{~m} / \mathrm{s}$ and occurred at a distance on average $\delta \approx 0.88 \mathrm{H}$. The experiments replicate typical flow conditions in smooth open channels at different flow depths and complement past research (see Table 1).

\subsection{Uniformity of the Flow}

Figure 7 shows the transverse profiles of streamwise time averaged velocity at different flow depths $(\mathrm{H})$. Transverse flow profiles were obtained along the total width of the channel. For each discharge, flow profiles were obtained at different depths $\mathrm{Y}$ depending on the water depth $\mathrm{H}$. In the case where the mean flow depth $\mathrm{H}$ is much smaller than the mean channel width (W), that is $\mathrm{H} / \mathrm{W}<1$, the flow can be considered approximately two-dimensional and the effect of the vertical velocity component can be neglected, where $\mathrm{x}$ and $\mathrm{z}$ respectively indicate the longitudinal and the transverse directions [8]. As seen in Fig. 7, $\mathrm{U} / \mathrm{U}_{\mathrm{m}}$ profiles along all the transverse direction (z) qualitatively represent the characteristics of the fully developed flow regime as described by Ben Meftah et al. [8] using the concept of shear layer development. This postulates the applicability of the law of the wall and other turbulent theories of smooth uniform open channel flows. Symmetry around the centre line is suggested with the channel centre at $Z=150 \mathrm{~mm}$ and hence the measurement grid of the LDV is very accurate after correcting for the laser light refraction.

\subsection{Shear velocities}

For a detailed investigation of the near-wall turbulence, it is very important to evaluate the shear velocity $U_{*}$ accurately. As shown in Table $4, U_{*}$ is evaluated from four different methods which are discussed above. In this study $U_{*}$ is determined from vertical profiles of the streamwise time averaged velocity measured at the centre of the channel in the fully developed flow region. For each water depth estimation of $\mathrm{U}_{* l}$ is based on fit to the $\log$ law assuming $\kappa=0.41$ and B-5.5 which are taken as typical values. Next, $\mathrm{U}_{*_{\mathrm{r}}}$ was determined $\mathbf{A Q 2}$ with the least-square method so that the data of $\overline{u^{\prime} v^{\prime}}$, gave the best fit to Equation;

$$
-\overline{u^{\prime} v^{\prime}}=U_{* r}^{2}\left(1-\frac{y}{H}\right)
$$

$\mathrm{U}_{*_{1}}$ and $\mathrm{U}_{*_{2}}$ are based on equations $U_{* 1}=\left(g R S_{e}\right)^{0.5}$ and $U_{* 2}=\left(g H S_{e}\right)^{0.5}$ respectively. Average percentage uncertainties calculated using the method of error propagation for $\mathrm{U}_{* 1}$, $\mathrm{U}_{*_{2}}, \mathrm{U}_{*_{\mathrm{r}}}$ and $\mathrm{U}_{*_{l}}$ are $2.8 \%, 1.5 \% 4.4 \%$ and $5.3 \%$ respectively. Both, $\mathrm{U}_{*_{l}}$ and $\mathrm{U}_{*_{\mathrm{r}}}$ seem to 


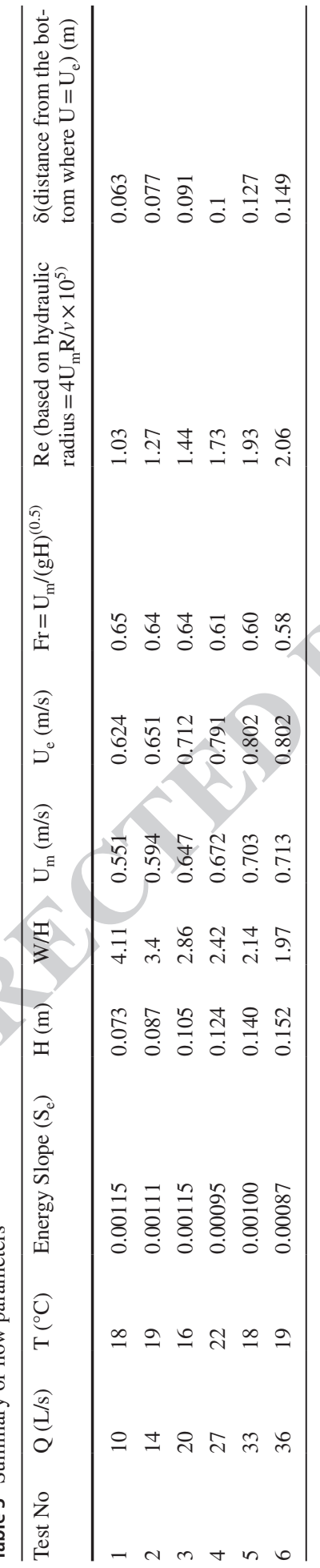



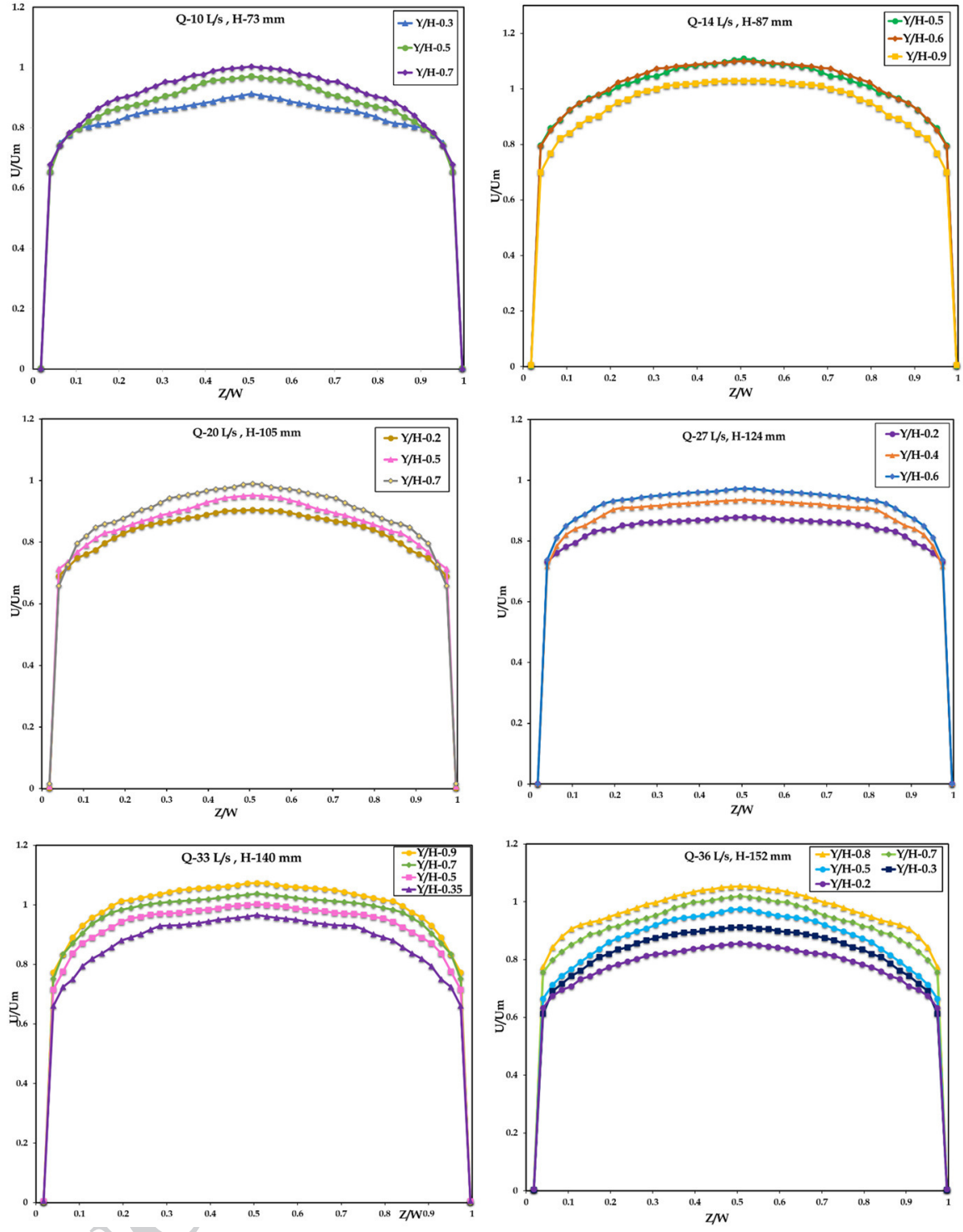

Fig. 7 Streamwise time averaged velocity profiles at different heights for varying flow rates

406 compare well with those given by Nezu and Rodi [38] and Kirkgoz [26] who found values 407 between 4.4 and $39.9 \mathrm{~mm} / \mathrm{s}$ for a similar range of Reynold numbers. $\mathrm{U}_{*_{1}}$ also does not dif408 fer more than $5 \%$ from $\mathrm{U}_{*_{l} l}$ and $\mathrm{U}_{*_{\mathrm{r}}}$ whereas $\mathrm{U}_{*_{2}}$ shows some deviation from $\mathrm{U}_{*_{l} l}$ and $\mathrm{U}_{*_{\mathrm{r}}}$

\subsection{Log law distribution}

As given in Eq. (4), firstly it is worth understanding why two different shear velocities are required in the log law as discussed above. It is always useful to measure the real $\mathrm{U}_{*}$ and 
Environmental Fluid Mechanics

Table 4 Shear velocities of experiments calculated from four methods

\begin{tabular}{lclllc}
\hline Test No & $\mathrm{H}(\mathrm{mm})$ & $\mathrm{U}_{*_{l}} \mathrm{~mm} / \mathrm{s}$ & $\mathrm{U}_{*_{1}}=\left(\mathrm{gRS}_{\mathrm{e}}\right)^{(0.5)} \mathrm{mm} / \mathrm{s}$ & $\mathrm{U}_{*_{2}}=\left(\mathrm{gHS}_{\mathrm{e}}\right)^{(0.5)} \mathrm{mm} / \mathrm{s}$ & $\mathrm{U}_{*_{\mathrm{r}}} \mathrm{mm} / \mathrm{s}$ \\
\hline 1 & 73 & 24.0 & 23.6 & 28.7 & 25.1 \\
2 & 87 & 24.9 & 24.5 & 30.8 & 25.0 \\
3 & 105 & 27.0 & 26.4 & 34.4 & 26.7 \\
4 & 124 & 26.3 & 25.2 & 34.0 & 27.3 \\
5 & 140 & 27.8 & 26.8 & 37.2 & 28.2 \\
6 & 152 & 26.8 & 25.3 & 35.9 & 29.9 \\
\hline
\end{tabular}

compare it with $\mathrm{U}_{*_{1}}$ and $\mathrm{U}_{*_{2}}$, but in the literature, there is a debate about whether $\mathrm{U}_{*_{1}}$ and $\mathrm{U}_{* 2}$ are equal or not. As discussed above, Tracy and Lester [59] concluded that the law of the wall is valid in the inner region of 3-D flows for a smooth channel, but shear velocities on either sides of the log law may differ from each other. However, they did not give any clarification as to why shear velocities are different in the log law. This assumption was firstly tested using the authors' own experimental data to confirm the both shear velocities are different in Eq. (4). Figure 8 shows typical results of measured mean velocity distribution in the central region for five different aspect ratios $(\mathrm{W} / \mathrm{H}$; where $\mathrm{W}$ is the channel width). The ordinate scale is the ratio of point velocity to local shear velocity, $U / U_{*_{2}}$ and the abscissa scale is the dimensionless depth, $\mathrm{U}_{*_{2}} \mathrm{y} / \mathrm{\nu}$; though lines have not been drawn through the points of each set of data, shown on Fig. 8 which is a semi-logarithmic plot, however they appear to define straight lines, each of which may be represented by an equation of the slope-intercept form but they do not have a common slope. Now the same data is replotted in the form of $U / U_{*_{1}}$ versus $U_{*_{2}} \mathrm{y} / \nu$ in Fig. 9, also in a semi-logarithmic plot. The semi-logarithmic plots of the streamwise component of the mean velocity profiles are shown in Fig. 9 for all the tests. Here, most importantly we used $U_{*_{1}}$ and $U_{*_{2}}$ in the $\log$

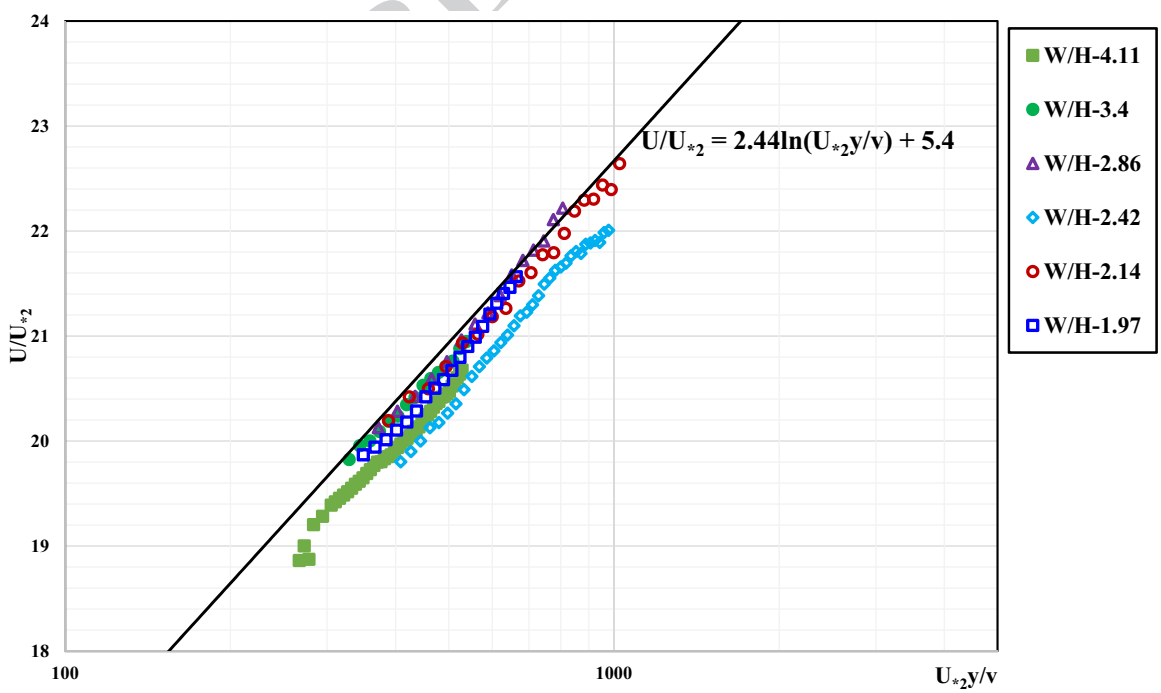

Fig. 8 The ratio of point velocity to local shear velocity, $U / U_{*_{2}}$ versus the dimensionless depth, $\mathrm{U}_{*_{2}} \mathrm{y} / \mathrm{v}$ 


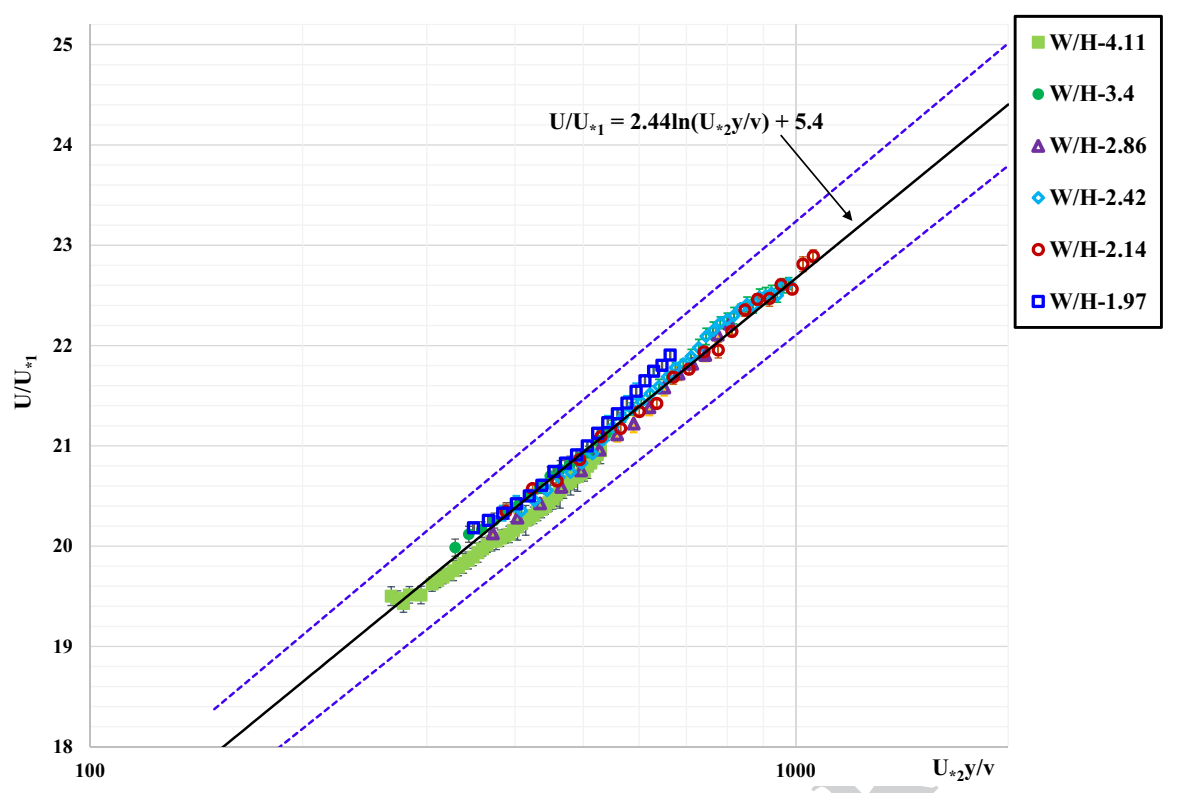

Fig. 9 Law of the wall distribution for all the aspect ratios

law (Eq: 4) as calculated from $U_{* 1}=\left(g R S_{e}\right)^{0.5}$ and $U_{* 2}=\left(g H S_{e}\right)^{0.5}$. The overall data in the turbulent part of inner region is best represented by Eq. 4 with A-2.44 and B-5.4 with a $R^{2}$ of 0.99 . It is worth noting that while obtaining the $U / U_{*_{1}}$ versus $U_{*_{2}} y / \nu$, uncertainties of each parameter (i.e. $U, U_{*_{1}}, U_{*_{2}}, y, \nu$ ) were considered individually and hence the errors of $U / U_{*_{1}}$ and $U_{*_{2}} y / \nu$ were calculated following the method of error propagation. As such, error bars which show the error of each data point and the $95 \%$ confidence band are also incorporated in Fig. 9.

Based on Fig. 8 i.e. the $\log$ law with $\mathrm{U}_{*_{2}}$ on both sides the calculated uncertainty of $\mathrm{B}$ is $20 \%$ by taking the value of B as 5.5 which is widely used by other researchers as given in Fig. 3. This uncertainty is reduced to less than 3\% with Eq. 4. Having noted in Sect. 4 that uncertainty of velocity measurements is less than $1.5 \%$ it is worth noting the higher uncertainty of $B$ when $U_{*_{2}}$ is used on both sides of the log law. Hence, it can be postulated that the use of $U_{*_{1}}$ and $U_{*_{2}}$ as given in Eq. (4) is a new representation of the log law which does not follow the typical use of $U_{*}$ on either side. In other words, this paper will not provide a new formulation, but provides a justification using our own experimental data, and the conclusion is also supported by the data from the literature as discussed in the following sections for wide and narrow channels irrespective of flow conditions. However, with this representation of the log law this research will contribute new knowledge with regards to the additive constant of the log law for the first time, which is also discussed in the following sections.

In Eq. (4), the value 2.44 is based on a von Karman universal constant $\kappa$ of 0.41 which is treated as a constant in this study. Table 5 shows the values obtained for the additive constant $\mathrm{B}$ and applicability range of the log law by presenting $\mathrm{y} / \mathrm{H}$ and $\mathrm{Re}^{*}$. The results are in perfect agreement with the published values of $\mathrm{B}$ as shown in Fig. 2 above. According to Nezu and Nakagawa [37] the log law is valid in the region of $\mathrm{y} / \mathrm{H}<0.2$ and $30<\mathrm{Y}+<0.2$ 
Table 5 Verification of log lawsome important statistics

\begin{tabular}{lllllll}
\hline Test No & $\begin{array}{l}\text { Aspect } \\
\text { ratio } \\
(\mathrm{W} / \mathrm{H})\end{array}$ & $\begin{array}{l}\text { Additive } \\
\text { constant } \\
(\mathrm{B})\end{array}$ & $(\mathrm{y} / \mathrm{H})_{\max }$ & $\mathrm{Re}^{*}$ & $\frac{\mathrm{U}_{* 2} \mathrm{y}}{v}$ & \\
\hline 1 & 4.11 & 5.34 & 0.25 & 1990 & 267 & 523 \\
2 & 3.40 & 5.23 & 0.22 & 2604 & 329 & 539 \\
3 & 2.86 & 5.23 & 0.25 & 3257 & 372 & 806 \\
4 & 2.42 & 5.69 & 0.22 & 4407 & 409 & 977 \\
5 & 2.14 & 5.47 & 0.19 & 4928 & 387 & 915 \\
6 & 1.97 & 5.73 & 0.13 & 5311 & 349 & 664 \\
Average & & 5.45 & & & & \\
STD & & 0.22 & & & & \\
\hline
\end{tabular}

$\mathrm{Re}^{*}$ which is in reasonable agreement with this study as well. However, some researchers (As an example, Zanoun [66]; Marusic et al. [30]) stated that the lower and upper limits of

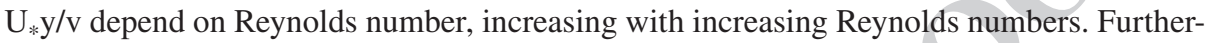
more, Cardoso et al. [13] analysed mean flow velocity data by taking the true inner region i.e. in which $\mathrm{y} / \mathrm{H}<0.2$ and the entire water depth $(\mathrm{y} / \mathrm{H}<1.0)$ and nearly the same mean values of $\kappa=0.40$ and $B \approx 5.1$ were achieved. This suggests that, for their data set, the law of the wall can be applied throughout the channel depth.

Figure 10 shows the integration constant $\mathrm{B}$ for the individual tests obtained against the Reynolds number Re which is defined based on hydraulic radius as $R e=4 U_{m} R / v$. The present data agrees well with the findings of Cardoso et al. [13] and Nezu and Rodi [38] who noted that for $10^{4}<\operatorname{Re}<10^{6}$ there is only a slight variability of additive constant $B$, which does not depend on the Reynolds number, especially in the case of uniform flows. As seen in Table 3, Fr number does not vary much for any of the test series, hence the influence of the Froude number cannot be analysed from our data because of its narrow range. The average value of B fell within the range found in the literature as $4<B<7$, summarised in Fig. 3. Though researchers found there is less scatter in $\kappa$, a significant scatter is evident in B. As an example, Nezu and Rodi [38] noted less scatter in $\kappa$ with $\kappa=0.412 \pm 0.11$, whereas considerable scatter in $\mathrm{B}$ was found with $\mathrm{B}=5.29 \pm 0.47$, as measured in boundary layers of open channels and pipe flow.

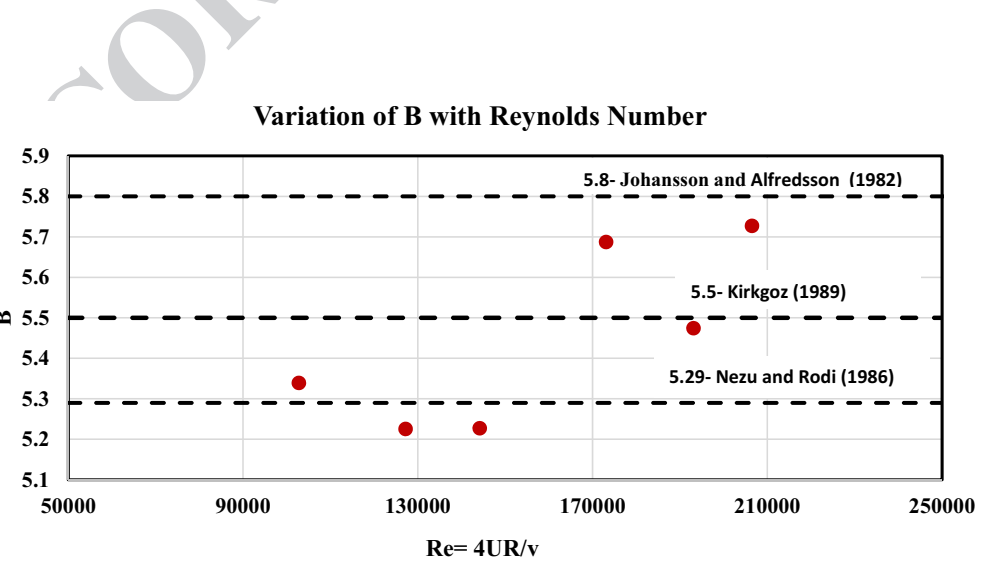

Fig. 10 Variation of B with Reynolds Number 
In order to further confirm the validity of Eq. (4), streamwise velocity (U) was calculated from Eq. (4) for all the tests. The calculated values were then compared with the measured streamwise velocity for each data set. Relative error was calculated for each data set using absolute difference of calculated and measured velocities for each data point using;

$$
\text { Relative Error }=\frac{\left|\left(U_{\text {calculated }}-U_{\text {measured }}\right)\right|}{U_{\text {measured }}} * 100 \%
$$

Then the average of relative errors of all the points was considered as the relative error of $U$ for that particular test. This procedure is repeated for all six tests and results are shown in Table 6 Moreover, the root mean square of error of $U$ was also calculated for 6 tests based on the calculated value of $U$ as in Eq. 4. Further, as discussed above (See Fig. 4 and Table 1), since $U_{*}$ calculated from different methods has been used in the log law, log law equations with $\mathrm{U}_{*_{l}}$ and $\mathrm{U}_{*_{\mathrm{r}}}$ have also been used to calculate $\mathrm{U}$ and then to calculate relative error as of Eq. (7). Only these two equations have been selected since those are deemed as typical representations of the log law representing $U_{*}$ from the different methods. Though use of $U_{*_{v}}$ in the log law is also common, unfortunately, due to the unavailability of data in the viscous sub layer, the log law with $U_{*_{v}}$ has not been used in this section. The percentage error of $U$ calculated from each method has been compared. As seen in the Table 6, Eq. (4) performs perfectly by indicating an error less than $1.5 \%$ for each test except test 6 . For all the tests our equation (Eq. (4)) performed very well compared to the log law equation with $U_{*_{\mathrm{r}}}$ As seen in Table 6 for Test 6, relative error of $U$ from this method (i.e. with $U_{*_{\mathrm{r}}}$ ) shows a relatively higher value for reasons unclear. Root mean square error calculated for all 6 experimental data sets based on Eq. 4 is also less than $1 \%$, which further confirms the validity of Eq. 4.

\subsection{Model verification}

Since Eq. (4) performs better for the experimental data obtained in this study, it is worth exploring the applicability of Eq. (4) with some data from the literature. For this purpose, a few data sets published in well-known journals have been selected. Firstly, all the data sets are selected from smooth open channel flows. Data sets were selected in a way representing both narrow and wide channels and subcritical and supercritical flow conditions. Although,

Table 6 Percentage error of $\mathrm{U}$ computed from log law with $\mathrm{U}_{* l}$, $\mathrm{U}_{*_{\mathrm{r}}}$ and Eq. 4

\begin{tabular}{llllll}
\hline Test No & $\begin{array}{c}\text { Water } \\
\text { depth } \\
(\mathrm{mm})\end{array}$ & W/H & \multicolumn{2}{l}{ \% error of U } \\
\cline { 4 - 6 } & & & $\begin{array}{l}\text { With } \mathrm{U}_{l} \text { in } \\
\text { log law }\end{array}$ & From Eq. (4) & $\begin{array}{l}\text { With } \mathrm{U}_{r} \text { in } \\
\log \text { law }\end{array}$ \\
\hline 1 & 73 & 4.11 & 2.2 & 1.2 & 4.9 \\
2 & 87 & 3.4 & 3.0 & 1.3 & 3.1 \\
3 & 105 & 2.86 & 1.7 & 1.3 & 1.3 \\
4 & 124 & 2.42 & 1.7 & 1.5 & 4.3 \\
5 & 140 & 2.14 & 1.6 & 1.3 & 2.0 \\
6 & 152 & 1.97 & 2.8 & 2.2 & 13.8 \\
\hline
\end{tabular}

$\frac{U}{U_{* 1}}=2.5 \ln \left(\frac{y U_{* 2}}{v}\right) 5.4$ Eq. (4) 
the vertical profiles of streamwise velocity in this study were obtained in the channel centre to check the validity of Eq. (4), data sets obtained near the wall were also selected. Hydraulic conditions for each data set are shown in Table 1, with some important information such as channel type, flow characteristics, velocity measurement techniques and shear velocity estimation methods. Even though a number of data sets have been considered, it is worth describing how the model is performing for three selected data sets in detail for more clarity (Table 7). Then results will be summarized in Table 8 . Table 8 gives the percentage error from each method for this data set. Hence, the following data sets and applicability with Eq. (4) are plotted and discussed.

The above authors' selected experimental data are plotted in Fig. 11 based on each author's log law representation as in Table 7. Then, the same data are re-plotted according to our representation of the log law which is as in Eq. (4) (see Fig. 12). Comparisons between the theoratical equations and the experimental data are made. Good agreement between the data and the Eq. (4) can be seen in Fig. 12 where Table 8 indicates the relative percentage error of calculated $U$ with the measured $U$ from each equation (as on Eq. 7). The results confirm the universality of Eq. (4), even for super critical flow conditions which is more interesting.

\subsubsection{Variation of $B^{\prime}$ and $H / R$}

Let us consider Eq. (5) again;

$$
B^{\prime}=\frac{1}{2} A \ln \left(\frac{H}{R}\right)+B
$$

$$
\frac{B^{\prime}}{B}=\frac{1}{2 B} A \ln \left(\frac{H}{R}\right)+1
$$

Since $\mathrm{A}=2.44$ and $\mathrm{B}=5.4$

$$
\frac{B^{\prime}}{B}=0.226 \ln \left(\frac{H}{R}\right)+1
$$

For a rectangular channel $\mathrm{H} / \mathrm{R}$ is directly related to the aspect ratio. (i.e.: $\mathrm{H} / \mathrm{R}=1+2 \mathrm{H} / \mathrm{W}$ ). For a wide rectangular channel since the channel width (W) is very large compare to water depth $(\mathrm{H})$ i.e. $\mathrm{R} \approx \mathrm{H}$; $\mathrm{B}^{\prime}$ will become $\mathrm{B}$. This is plotted in Fig. 13. Both experimental data in this study and data from the literature have been used to validate Eq. (8) (See Appendix). The selected data represents the data only from rectangular open channel flows where aspect ratios $(\mathrm{W} / \mathrm{H})$ are in the range of 2 to 23 which represents wide range of aspect ratios $[31,34,42,53]$. As seen in Fig. 13 it is evident that when $H / R$ tends to $1, B^{\prime}$ tends to $\mathrm{B}$ which is the typical additive constant of the log law. This postulates that the additive constant B of log law is a function of aspect ratio and hence depend on channel geometry. This adds a novel contribution to the exiting knowledge of log law in open channel flows. Moreover, this further postulates the validity of Eq. (4). 


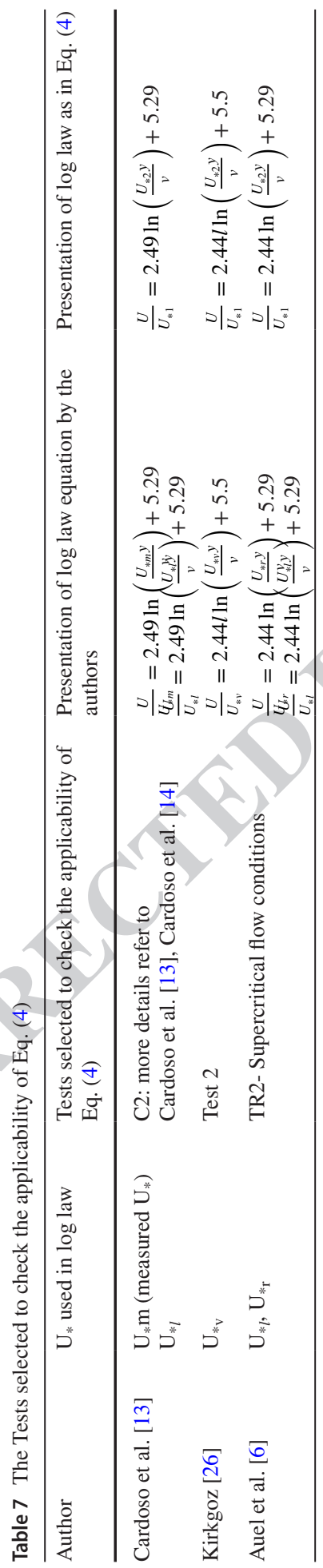




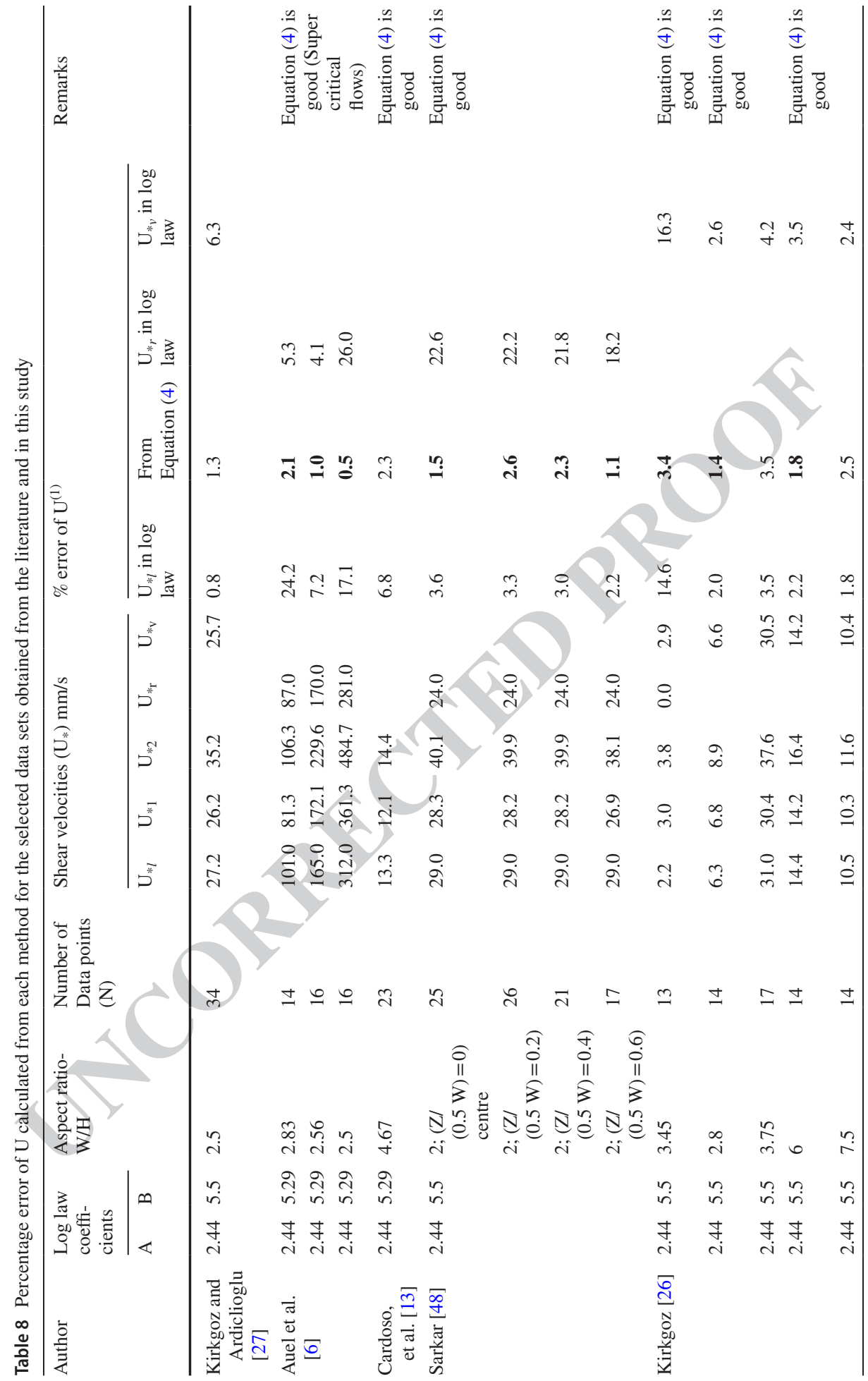




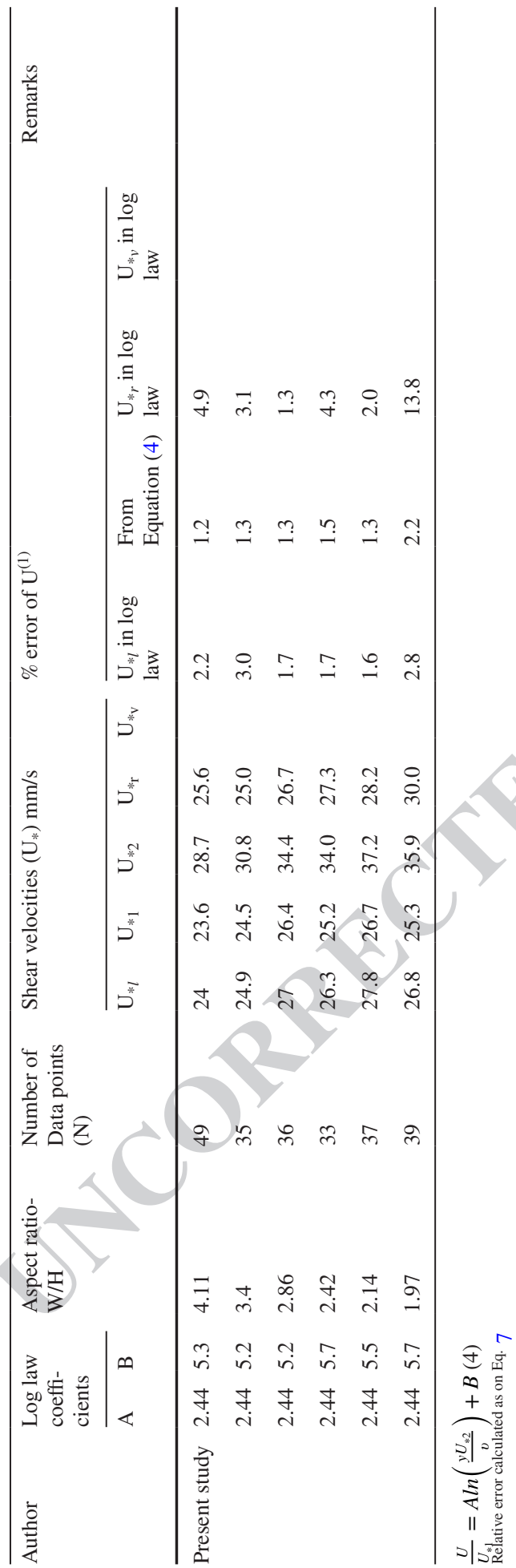




\section{Environmental Fluid Mechanics}

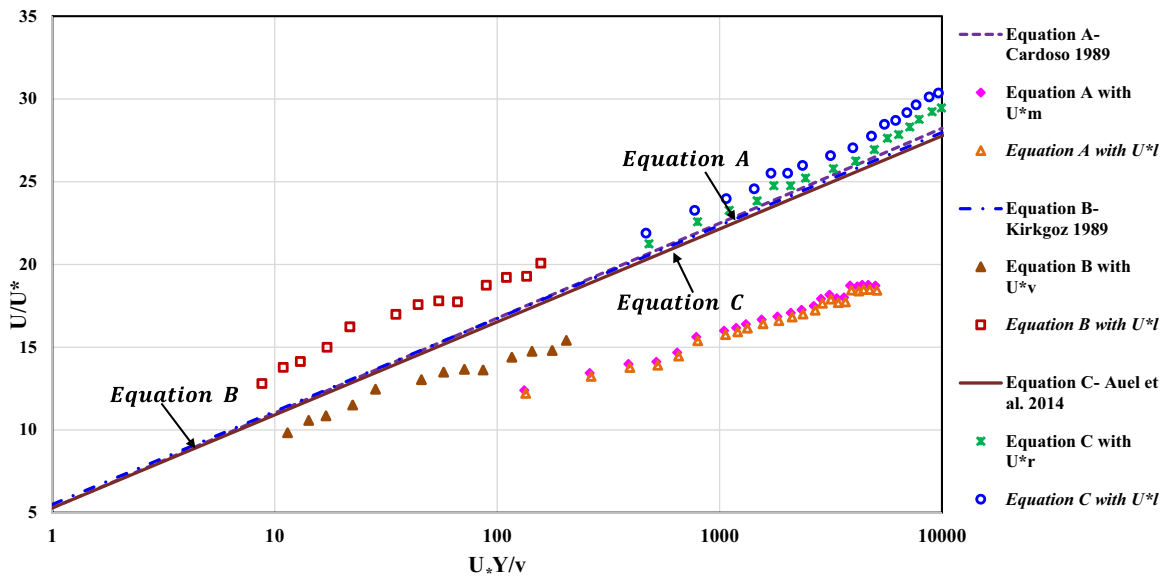

$\frac{U}{U_{v}}=2.49 \ln \left(\frac{U_{*} y}{v}\right)+5.29$ Equation A Cardoso 1989; $\frac{U}{U_{*}}=2.44 l \ln \left(\frac{U_{*} y}{v}\right)+5.5$ Equation B Kirkgoz 1989; $\frac{U}{U_{*}}=2.44 \ln \left(\frac{U_{*} y}{v^{\prime}}\right)+5.29$ Equation C Auel et.al 2014

Fig. 11 Presentation of Log law distribution as Equation A Cardoso [13]; Equation B Kirkgoz [26] and Equation C Auel et al. [6]

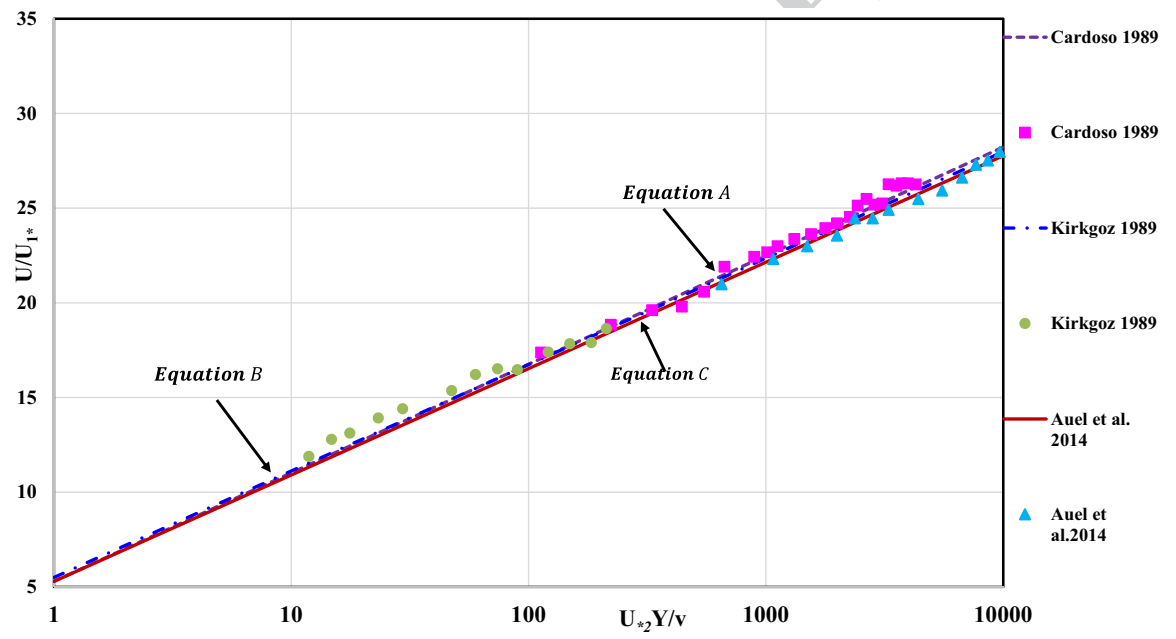

$\frac{U}{U_{*}}=2.49 \ln \left(\frac{U_{* m} y}{v}\right)+5.29$ Equation A Cardoso 1989; $\frac{U}{U_{*}}=2.44 l \ln \left(\frac{U_{*} y}{v}\right)+5.5$ Equation B Kirkgoz 1989; $\frac{U}{U_{*}}=2.44 \ln \left(\frac{U_{*} y}{v}\right)+5.29$ Equation C Auel et al. 2014

Fig. 12 Log law distribution- Eq. (4)-Data obtained from Cardoso [13]; Kirkgoz [26] and Auel et al. [6] 


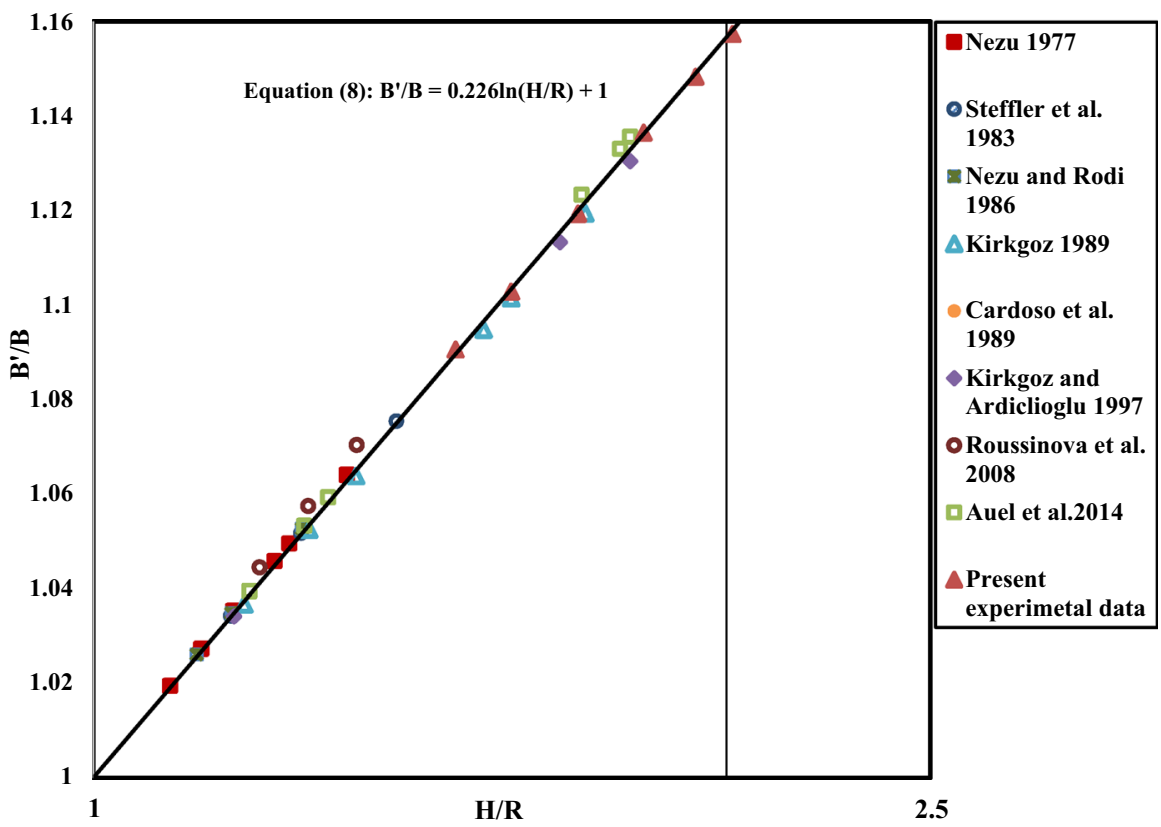

Fig. 13 Validation of Eq. (8) with experimental data

\section{Conclusions}

Methodical 2D-LDV velocity measurements were conducted in a smooth, uniform, narrow open channel at steady, subcritical flow conditions. Both transverse and vertical profiles of streamwise velocities were measured. Six sets of experiments were conducted pertinent to six different aspect ratios. The transverse profiles of streamwise time averaged velocity distributions indicate a quasi-symmetrical pattern with maximum velocities at the flume centre and decreasing velocities in the near side wall and bottom region.

The dip phenomenon is well pronounced in this study as all tests were conducted on a narrow channel where the aspect ratio is less than 5 . Maximum velocities were observed at an average distance of $\mathrm{Q} \approx 0.88 \mathrm{H}$ for all experiments. This indicates that the outer flow region is affected by well-developed surface and bottom vortices, i.e., secondary currents at the side walls. These currents create three-dimensional flow patterns.

Friction velocities are evaluated and fitted to a typical log law, from the measured Reynolds shear stress distribution and using the slope of the energy line. Energy slope was used to evaluate global shear velocity $\left(\mathrm{U}_{*_{1}}\right)$ and local shear velocity $\left(\mathrm{U}_{*_{2}}\right)$. Theoretical studies of Tracy and Lester [59] and Yang et al. [63] highlight that the shear velocities on both sides of the classical log-law are different due to the influence of secondary currents. It is 
found that the classical log law gives a good description of the velocity distribution in the inner region if the global shear velocity and local shear velocity are introduced as a velocity scale and length scale respectively as $\mathrm{U} / \mathrm{U}_{*_{1}}$ and as the dimensionless distance, i.e., $\mathrm{U}_{*_{2}} \mathrm{y} / \mathrm{v}$ where: $\mathrm{U}_{*_{1}}=\left(\mathrm{gRS}_{\mathrm{e}}\right)^{0.5}$ and $\mathrm{U}_{*_{2}}=\left(\mathrm{gHS}_{\mathrm{e}}\right)^{0.5}$. With these new scalings (Eq. (4)) the experimental velocity profiles agree well with the logarithmic law of the wall distribution, for coefficients $A=2.44$ and $B=5.4$. The developed model i.e. Equation (4) is verified with experimental data from past research, which depicts high accuracy. Most interestingly it is worth noting that these scalings are valid for smooth narrow or wide channels for both supercritical and subcritical conditions which hence supports the universal applicability of Eq. (4).

Moreover, according to the critical review conducted, past literature questioned the universality of the von Karman constant $\kappa$ in the log law equation as well as the large scatter of the additive constant; B. This is further explored using Eq. (8) by defining B', which depends on $\mathrm{B}$. The authors suggest that $\mathrm{B}^{\prime}$ is more practical to use in place of $\mathrm{B}$ where for wide channels $\mathrm{B}^{\prime}$ eventually tends to $\mathrm{B}$ which is the typical additive constant of the $\log$ law. In addition it is shown that $\mathrm{B}^{\prime} / \mathrm{B}$ is indeed related to the aspect ratio. From this we can postulate that the additive constant; B in the log law is obviously a function of channel aspect ratio, and depends on channel geometry.

To summarize, the results of the present study yield an important step towards the understanding of the log law velocity profile in smooth uniform open channel flows over a range of Reynolds numbers and moderately high Froude numbers. The experimental data obtained by the authors from this study and from the past literature strongly verified the applicability of the Eq. (4) irrespective of channel characteristics. Finally, it is evident that extensive data obtained from LDV will facilitate the more rigorous understanding of the mean flow and turbulent structure in smooth open channel flow.

\section{Appendix}

See Table 9. 


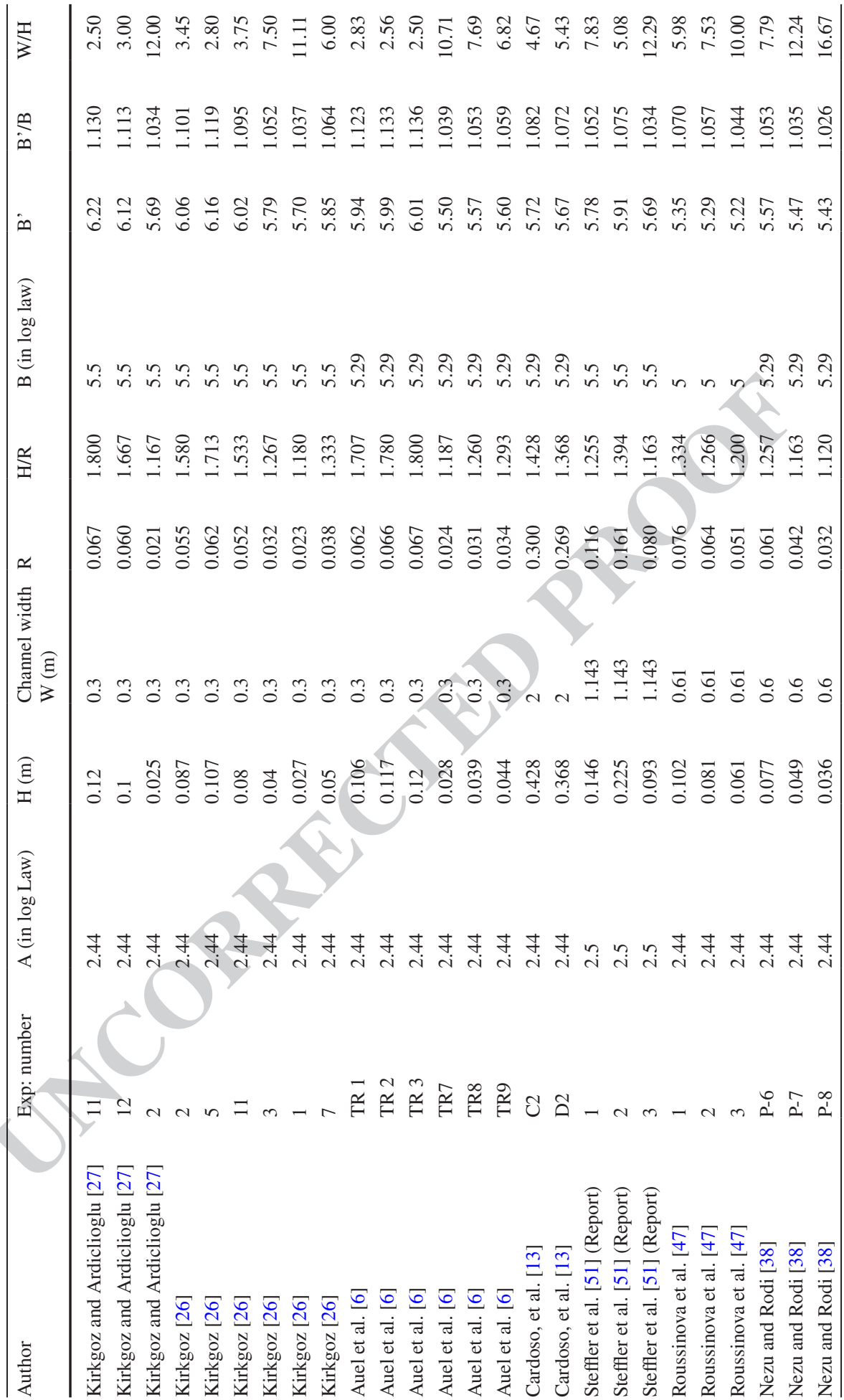




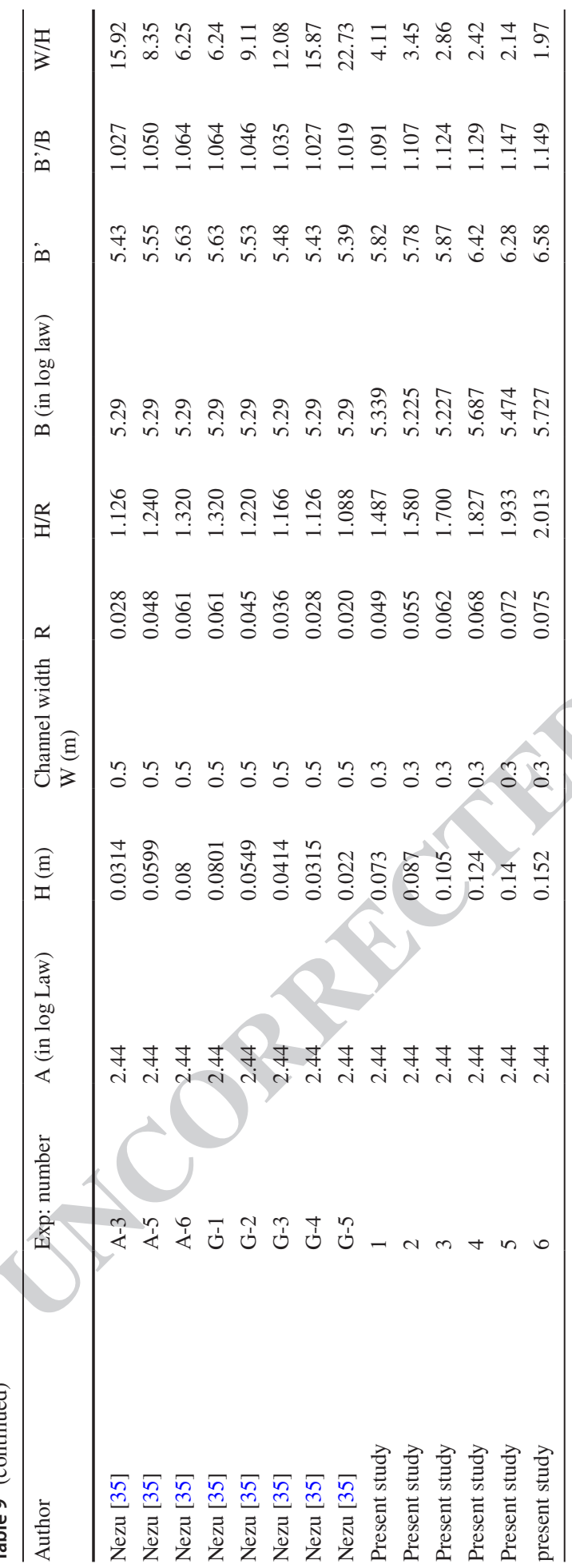




\section{References}

1. Absi R (2011) An ordinary differential equation for velocity distribution and dip-phenomenon in open channel flows. J Hydraul Res 49(1):82-89. https://doi.org/10.1080/00221686.2010.535700

2. Al Faruque MA, Wolcott S, Goldowitz J, Wolcott T (2014) Open channel flow velocity profiles for different Reynolds numbers and roughness conditions. Int J Res Eng Tech 03(01):400-405.

3. Asgari Kaji MH (2013) Turbulent structure in open channel flow, MSc Thesis. University of Windsor

4. ASHRAE Guideline (1986) Engineering analysis of experimental data. American Society of Heating, Refrigerating and Air-Conditioning Enginners, Inc, Atlanta

5. Aubertine CD, Eaton JK (2005) Turbulence development in a non-equilibrium turbulent boundary layer with mild adverse pressure gradient. J Fluid Mech 532:345-364. https://doi.org/10.1017/S0022 112005004143

6. Auel C, Albayrak I, Boes RM (2014) Turbulence characteristics in supercritical open channel flows: effects of Froude number and aspect ratio. J Hydraul Eng 140(4):04014004-1-16. https://doi. org/10.1061/(asce)hy.1943-7900.0000841

7. Balachandar R, Blakely D, Tachie M, Putz G (2001) A study on turbulent boundary layers on a smooth flat plate in an open channel. J Fluid Eng-T ASME 123(2):394-400

8. Ben Meftah M, De Serio F, Mossa M (2014) Hydrodynamic behavior in the outer shear layer of partly obstructed open channels. Phys Fluids 26(6):065102. https://doi.org/10.1063/1.4881425

9. Ben Meftah M, Mossa M (2016) A modified log-law of flow velocity distribution in partly obstructed open channels. Environ Fluid Mech 16(2):453-479

10. Bevington PR, Robinson DK, Blair JM, Mallinckrodt AJ, McKay S (1993) Data reduction and error analysis for the physical sciences. Comput Phys 7(4):415-416

11. Blakely D, Tachie M, Putz G (2001) A study on turbulent boundary layers on a smooth flat plate in an open channel

12. Bonakdari H, Larrarte F, Lassabatere L, Joannis C (2008) Turbulent velocity profile in fully-developed open channel flows. Environ Fluid Mech 8(1):1-17. https://doi.org/10.1007/s10652-007-9051-6

13. Cardoso A, Graf WH, Gust G (1989) Uniform flow in a smooth open channel. J Hydraul Res 27(5):603-616. https://doi.org/10.1080/00221688909499113

14. Cardoso A, Graf WH, Gust G (1991) Steady gradually accelerating flow in a smooth open channel. J Hydraul Res 29(4):525-543. https://doi.org/10.1080/00221689109498972

15. Cebeci T (2013) Analysis of turbulent flows with computer programs. Butterworth-Heinemann, Oxford

16. Dantec (1995) Dantec measurment technology, fibre flow installation and user's guide

17. Dantec (2011) LDA and PDA reference manual

18. Durst F, Melling A, Whitelaw JH (1981) Principles and practice of laser-Doppler anemometry. Academic Press, London

19. Gamage NCDKL (2012) Macro turbulent characteristics over two-dimensional bed forms and its skin friction and form drag separation, PhD Thesis. University of Wollongong

20. George WK, Castillo L, Knecht P (1997) Zero-pressure-gradient turbulent boundary layer. Appl Mech Rev 50:689-730. https://doi.org/10.1115/1.3101858

21. Guo J (1998) Turbulent velocity profiles in clear water and sediment-laden flows, PhD Thesis. Colorado State University Fort Collins, CO

22. Han Y (2014) Experimental verification of flow divisibility in 3-D laboratory channels, PhD Thesis. University of Wollongong

23. Han Y, Yang S-Q, Dharmasiri N, Sivakumar M (2014) Effects of sample size and concentration of seeding in LDA measurements on the velocity bias in open channel flow. Flow Meas Instrum 38:9297. https://doi.org/10.1016/j.flowmeasinst.2014.05.008

24. Huffman GD, Bradshaw P (1972) A note on von Karman's constant in low Reynolds number turbulent flows. J Fluid Mech 53(1):45-60. https://doi.org/10.1017/S0022112072000035

25. Keulegan GH (1938) Laws of turbulent flow in open channels, vol 21. National Bureau of Standards US

26. Kirkgoz MS (1989) Turbulent velocity profiles for smooth and rough open channel flow. J Hydraul Eng 115(11):1543-1561

27. Kirkgoz MS, Ardiclioglu M (1997) Velocity profiles of developing and developed open channel flow. J Hydraul Eng 123(12):1099-1105. https://doi.org/10.1061/(ASCE)07339429(1997)123:12(1099)

28. Kironoto B, Graf WH, Song T, Lemmin U (1994) Turbulence characteristics in rough uniform openchannel flow. In: Proceedings of the Institution of Civil Engineers. Water, maritime and energy, vol 106(4), pp 333-344. https://doi.org/10.1680/iwtme.1994.27234

29. Konstantinidis E (2001) Pulsating flow in cylinder arrays. University of London, London 
30. Marusic I, McKeon B, Monkewitz PA, Nagib H, Smits A, Sreenivasan K (2010) Wall-bounded turbulent flows at high Reynolds numbers: recent advances and key issues. Phys Fluids 22(6):065103. https ://doi.org/10.1063/1.3453711

31. McGahey C, Samuels PG, Knight DW (2006) A practical approach to estimating the flow capacity of rivers-application and analysis. River Flow 2006:303-312

32. Moffat R (1982) Contributions to the theory of single-sample uncertainty analysis. J Fluid Eng-T ASME 104(2):250-258

33. Nagib HM, Chauhan KA (2008) Variations of von Karman coefficient in canonical flows. Phys Fluids 20(10):101518. https://doi.org/10.1063/1.3006423

34. Nekouee N, Roberts PJW, Schwab DJ, McCormick MJ (2012) Classification of buoyant river plumes from large aspect ratio channels. J Hydraul Eng 139(3):296-309. https://doi.org/10.1061/\%28ASC E\%29HY.1943-7900.0000651

35. Nezu I (1977) Turbulent structure in open-channel flows. English translation of the Japanese dissertation of Iehisa Nezu

36. Nezu I (2005) Open-channel flow turbulence and its research prospect in the 21st century. J Hydraul Eng 131(4):229-246. https://doi.org/10.1061/(ASCE)0733-9429(2005)131:4(229)

37. Nezu I, Nakagawa H (1993) Turbulence in open channels. IAHR/AIRH Monograph. Balkema, Rotterdam

38. Nezu I, Rodi W (1986) Open-channel flow measurements with a laser Doppler anemometer. J Hydraul Eng 112(5):335-355. https://doi.org/10.1061/(ASCE)0733-9429(1986)112:5(335)

39. Nezu I, Sanjou M (2011) PIV and PTV measurements in hydro-sciences with focus on turbulent openchannel flows. J Hydro-Environ Res 5(4):215-230. https://doi.org/10.1016/j.jher.2011.05.004

40. NHRI (1957) Experimental study on 3-D velocity distribution in smooth open channel flow. Res Rep Nanjing Hydraul Res Inst, Nanjing

41. Nikuradse J (1933) Laws of flow in rough pipes. In: VDI Forschungsheft. Citeseer

42. Ohara N, Yamatani K (2019) Theoretical stable hydraulic section based on the principle of Least Action. Sci Rep 9(1):7957

43. Peltier Y, Rivière N, Proust S, Mignot E, Paquier A, Shiono K (2013) Estimation of the error on the mean velocity and on the Reynolds stress due to a misoriented ADV probe in the horizontal plane: case of experiments in a compound open-channel. Flow Meas Instrum 34:34-41. https://doi.org/10.1016/j. flowmeasinst.2013.08.002

44. Prandtl L (1932) Recent results of turbulent research, translation by National Advisory Committee for Aeronautics. TM

45. Prinos P, Zeris A (1995) Uniform flow in open channels with steep slopes. J Hydraul Res 33(5):705719. https://doi.org/10.1080/00221689509498566

46. Roussinova V (2009) Turbulent structures in smooth and rough open channel flows: effect of depth. University of Windsor, Windsor

47. Roussinova V, Biswas N, Balachandar R (2008) Revisiting turbulence in smooth uniform open channel flow. J Hydraul Res 46(sup1):36-48

48. Sarkar S (2016) Measurement of turbulent flow in a narrow open channel. J Hydrol Hydromech 64(3):273-280. https://doi.org/10.1515/johh-2016-0018

49. Sarma KV, Lakshminarayana P, Rao NL (1983) Velocity distribution in smooth rectangular open channels. J Hydraul Eng 109(2):270-289. https://doi.org/10.1061/(ASCE)0733-9429(1983)

50. Schlichting H (1979) Boundary-layer theory, 6th edn. Translation by Kestin J. Chaps 14 and 20. McGraw-Hill, New York

51. Steffler PM, Rajaratnam N, Peterson A (1983) LDA measurements of mean velocity and turbulence distribution in a smooth rectangular open channel. Department of Civil Engineering, University of Alberta, Alberta

52. Steffler PM, Rajaratnam N, Peterson AW (1985) LDA measurements in open channel. J Hydraul Eng 111(1):119-130. https://doi.org/10.1061/(ASCE)0733-9429(1985)

53. Swartz JM, Gulick SPS, Goff JA (2015) Gulf of A laska continental slope morphology: evidence for recent trough mouth fan formation. Geochem Geophys Geosyst 16(1):165-177. https://doi. org/10.1002/2014GC005594

54. Tachie M, Bergstrom D, Balachandar R (2003) Roughness effects in low-Re $\theta$ open-channel turbulent boundary layers. Exp Fluids 35(4):338-346

55. Taylor J (1997) Introduction to error analysis, the study of uncertainties in physical measurements

56. Tominaga A, Nezu I (1991) Turbulent structure in compound open-channel flows. J Hydraul Eng 117(1):21-41. https://doi.org/10.1061/(ASCE)0733-9429(1991)

57. Townsend AA (1980) The structure of turbulent shear flow. Cambridge University Press, Cambridge 
58. Tracy HJ (1963) Turbulent flow in a three-dimensional channel. Georgia Institute of Technology, Atlanta

59. Tracy HJ, Lester C (1961) Resistance coefficients and velocity distribution smooth rectangular channel. US Government Printing Office, Washington, DC

60. Vinuesa R, Schlatter P, Nagib HM (2015) On minimum aspect ratio for duct flow facilities and the role of side walls in generating secondary flows. J Turbul 16(6):588-606. https://doi.org/10.1080/14685 248.2014 .996716

61. von Karman T (1946) On laminar and turbulent friction. Technical Memorandum. No. 1992

62. Yang S-Q (2010) Depth-averaged shear stress and velocity in open-channel flows. J Hydraul Eng ASCE. https://doi.org/10.1061/(asce)hy.1943-7900.0000271

63. Yang S-Q, Lim S-Y, McCorquodale J (2005) Investigation of near wall velocity in 3-D smooth channel flows. J Hydraul Res 43(2):149-157. https://doi.org/10.1080/00221686.2005.9641231

64. Yang S-Q, Tan S-K, Lim S-Y (2004) Velocity distribution and dip-phenomenon in smooth uniform open channel flows. J Hydraul Eng 130(12):1179-1186. https://doi.org/10.1061/ (ASCE)0733-9429(2004)130:12(1179)

65. Yassin AM (1953) Mean roughness coefficient in open channels with different roughnesses of bed and side walls. ETH Zurich, Zurich

66. Zanoun E-S, Durst F, Nagib H (2003) Evaluating the law of the wall in two-dimensional fully developed turbulent channel flows. Phys Fluids 15(10):3079-3089. https://doi.org/10.1063/1.1608010

67. Zhang Z (2002) Velocity bias in LDA measurements and its dependence on the flow turbulence. Flow Meas Instrum 13(3):63-68. https://doi.org/10.1016/S0955-5986(02)00029-8

Publisher's Note Springer Nature remains neutral with regard to jurisdictional claims in published maps and institutional affiliations.

\title{
Affiliations
}

\section{Nadeeka S. Miguntanna ${ }^{1}\left[\right.$. Hamish Moses $^{1} \cdot$ Muttucumaru Sivakumar $^{1}$. Shuqing Yang ${ }^{1} \cdot$ Keith Enever ${ }^{2} \cdot$ Muhammad Zain Bin Riaz $^{1}$}

\author{
Hamish Moses \\ hsm975@uowmail.edu.au \\ Muttucumaru Sivakumar \\ siva@uow.edu.au

\section{Shuqing Yang} \\ shuqing@uow.edu.au \\ Keith Enever \\ kenever@uow.edu.au \\ Muhammad Zain Bin Riaz \\ mzbr518@uowmail.edu.au
}

1 School of Civil, Mining and Environmental Engineering, Faculty of Engineering and Information

Sciences, University of Wollongong, Wollongong, Australia

2 School of Mechanical, Materials, Mechatronics and Biomedical Engineering, Faculty of Engineering and Information Sciences, University of Wollongong, Wollongong, Australia 
Journal: $\quad \mathbf{1 0 6 5 2}$

Article:9733

\section{Author Query Form}

\section{Please ensure you fill out your response to the queries raised below and return this form along with your corrections}

\section{Dear Author}

During the process of typesetting your article, the following queries have arisen. Please check your typeset proof carefully against the queries listed below and mark the necessary changes either directly on the proof/online grid or in the 'Author's response' area provided below

\begin{tabular}{|l|l|l|}
\hline Query & Details Required & $\begin{array}{l}\text { A u t h o r' s } \\
\text { Response }\end{array}$ \\
\hline AQ1 & $\begin{array}{l}\text { Please confirm if the author names are presented accurately } \\
\text { and in the correct sequence (given name, family name). } \\
\text { Author 3 Given name: [Muhammad Zain Bin] Last name } \\
{[\text { Riaz]. Also, kindly confirm the details in the metadata are }} \\
\text { correct. }\end{array}$ & \\
\hline AQ2 & $\begin{array}{l}\text { Please check the edit made in the sentencce "Next, U*r } \\
\text { was determined with... is correct. }\end{array}$ & \\
\hline AQ3 & $\begin{array}{l}\text { Please provide a definition for the significance of bold in } \\
\text { the table 8. }\end{array}$ & \\
\hline AQ4 & $\begin{array}{l}\text { Please check and confirm figures and tables captions are } \\
\text { correctly identified. }\end{array}$ & \\
\hline AQ5 & Please update references [11, 16, 17, 41, 55]. & \\
\hline
\end{tabular}

